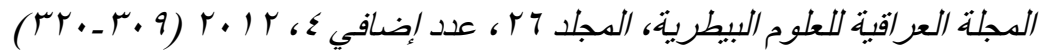

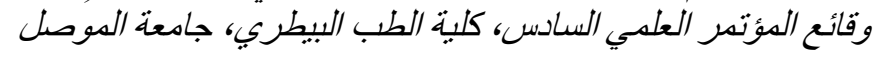

$$
\begin{aligned}
& \text { عزل الفيروس الحئي البقري النمطا من الأبقار في سوريا } \\
& \text { صفوان يوسف البارودي، عزام كردي و أنور العمر } \\
& \text { قسم الأحياء الدقيقة، كلية الطب البيطري، جامعة البعث، سوريا }
\end{aligned}
$$

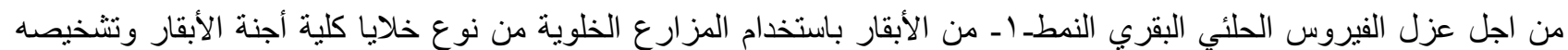

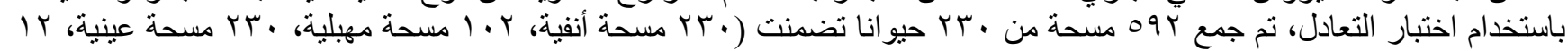

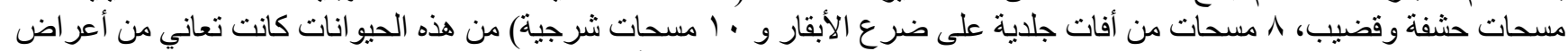

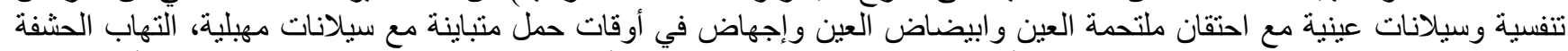

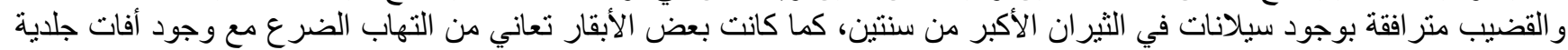

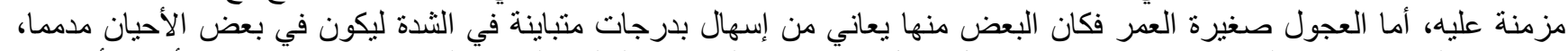

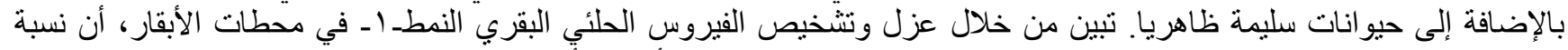

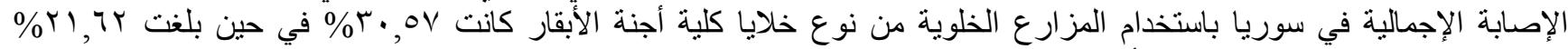

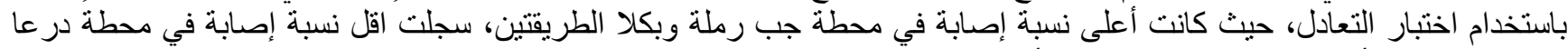

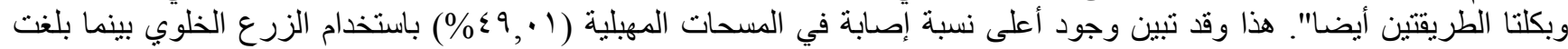

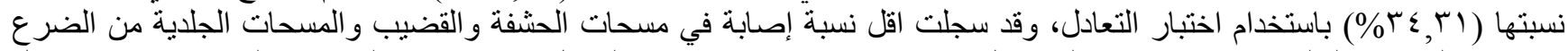

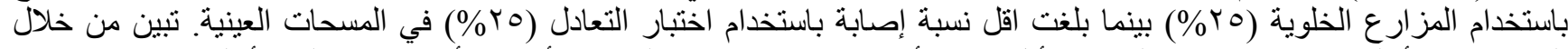

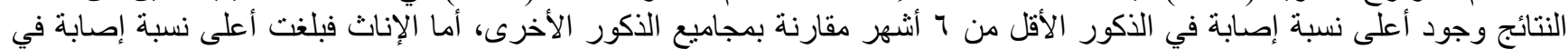

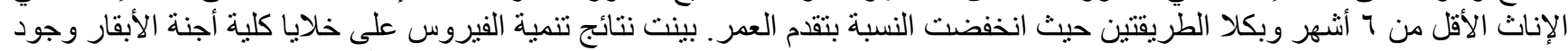

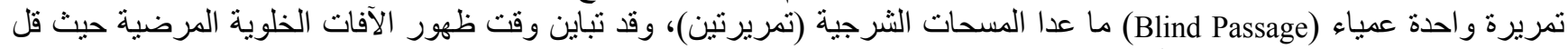

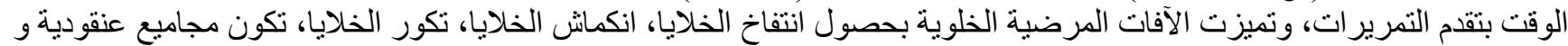
فجو ات، حيث تباينت هذه الآفات في التمريرات اعتمادا على نوع العينة، حيث كان أكثر ها شدة في مسحات الحشفة والقضيب لئي مقارنة بيقية

\title{
Isolation of bovine herpes virus type-1 (BHV-1) from cattle in Syria
}

\author{
S. Y. AL-Baroodi, A. Kurdi and A. Alomar
}

Department of Microbiology, Faculty of Veterinary Medicine, Albaath University, Syria

\begin{abstract}
In order to isolate Bovine Herpes virus type -1- (BHV-1) from cattle using cell culture (Bovine fetal kidney cell) and diagnosis by neutralization test, 592 swabs (230 Nasal swabs, 102 Vaginal swabs, 230 Ocular swabs, 12 swabs from Balanus and penises, 8 swabs from skin lesion in udder and 10 Anal swabs) were collected from animals suffering from respiratory signs, ocular discharge with congestion in conjugtiva and opacity in the eye, abortion in different stages of pregnancy with vaginal discharge, inflammation in balanus and penis with discharge in ox older than 2 years, some cattle suffering from mastitis with chronic skin lesions in udder and teat, some young calves suffer from bloody diarrhea, and healthy cattle. The result of isolation and diagnosis of virus showed (30.57\%) total percentage of infection using cell culture and (21.62\%) using neutralization test. The highest percentage of infection was in Jub ramla farm, and the lowest percentage infection was in Dura farm using both methods. The study also showed the high percentage in vaginal swabs $(49.01 \%)$ in cell culture, and in neutralization test $(34.31 \%)$, whereas the lowest percentage of infection appeared in swabs from balanus and penises and swabs from skin lesion in udder (25\%) in cell culture, while the lowest percentage of infection (25\%) appeared in ocular swabs
\end{abstract}




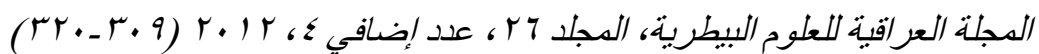

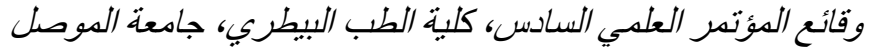

using neutralization test. The study detected the high percentage of infection in young calves (less than 6 months) of both sex by using both methods. The results of propagation of samples in cell culture appear one blind passage except anal swabs (two blind passage), the cytopathic effect (CPE) differ in appearance as the time decrease with progress passage. The CPE manifested by cell swelling shrink and rounded of cells. Cluster appearance and Vacuoles. The CPE variad in passage depending on type of sample, the highest potency was in balanus and penises swabs when compared with other samples.

Available online at http://www.vetmedmosul.org/ijvs

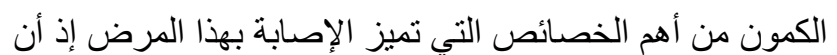

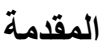

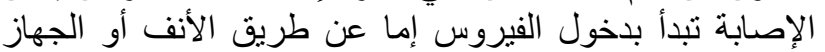

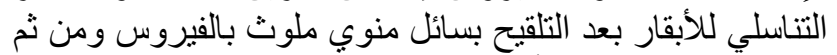
يتكاثر الفيروس في الأغشية المخاطية ومن ثم ينتقل للام مسبيا

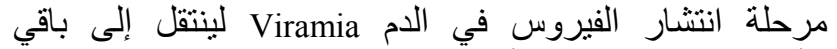

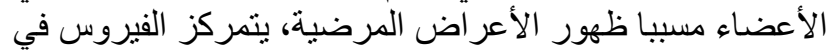

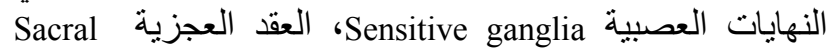
ganglia

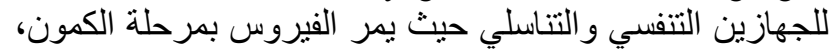

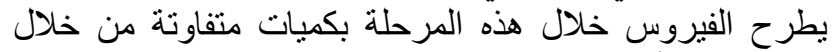

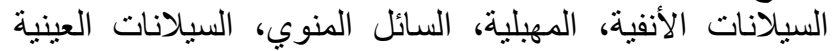

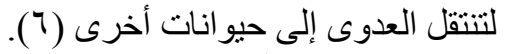
ينت تثخيص العيى الفيروس بعدة طرق أخرى منها التقصي عن الأضداد

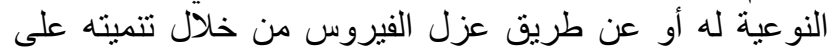

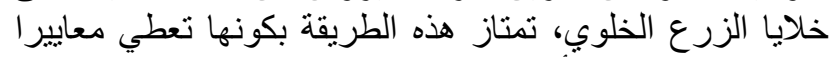

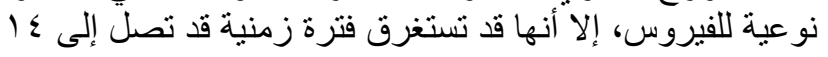

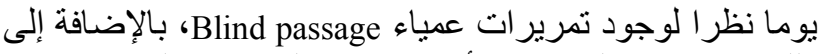

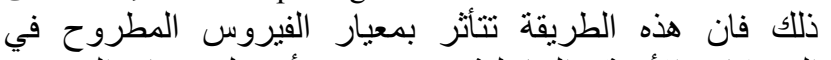

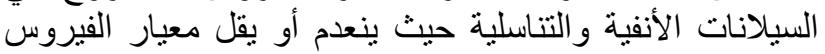

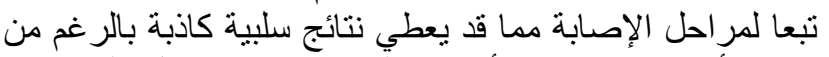

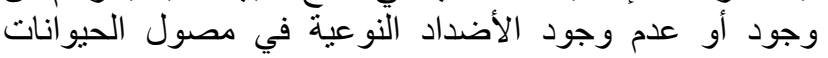

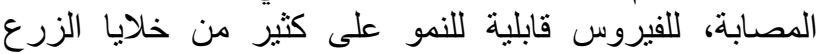

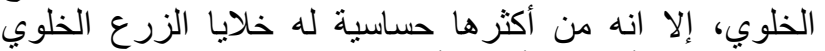

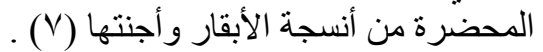

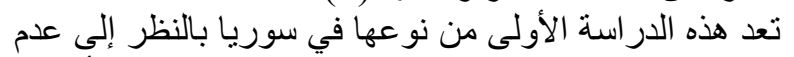

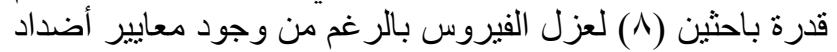

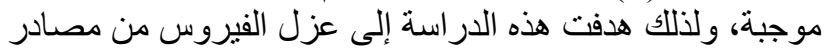

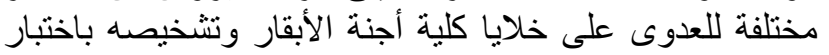

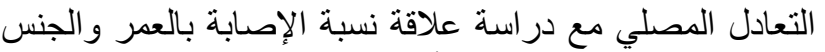
و الموقع الجغر آفي لمحطات الأبقار في سوريا.

\section{المواد وطرائق العمل}

\section{الحيوانات}

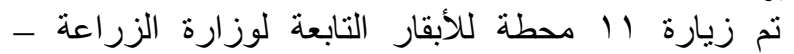

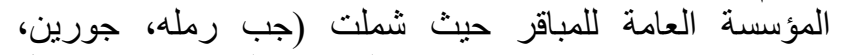

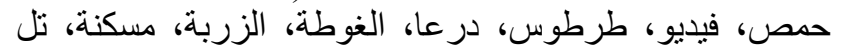

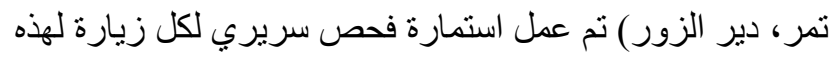

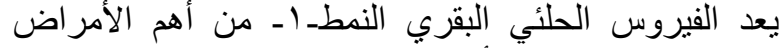
الفيروسية التي تصيب الأبقار، يعود هذا الفيرئ الفيروس إلى اللى عائلة

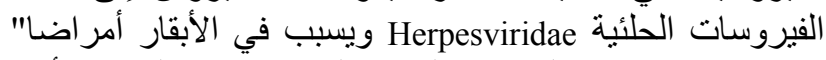

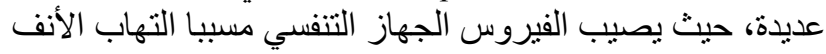
و الرغامي الخمجي البقري (IBR) Rhinotrachitis و الذي يتر افق مع إصابة الجهاز التتفسي العلوي التئي

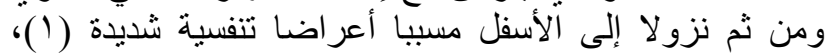

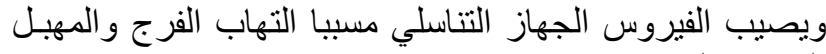

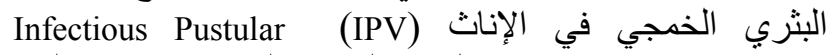
Vulvovaginitis

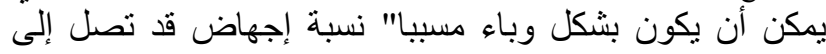

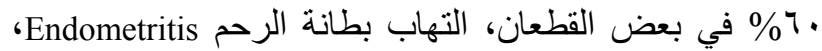

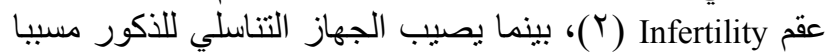
التهاب الحثفة والقضيب البثري الخمجي في الثثيران (IPB) Infectious Pustular Balanopsthitis مسببة العقم (r)، يصيب الفيروس أيضا" العين مسببا التهاب

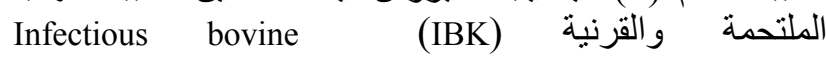
keratoconjunctivitis

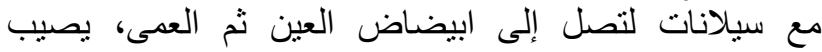

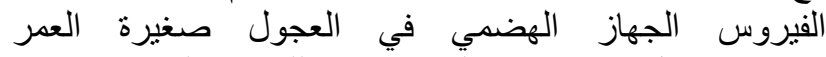
مسببا"الإسهال، بالإضافة إلى إصابته للجهاز العصبي مسببا لإنيا

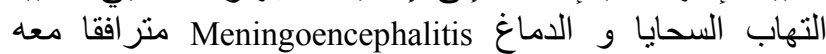

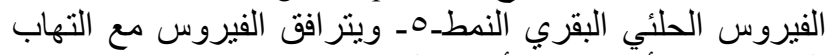

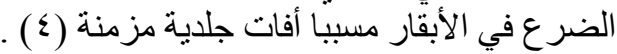

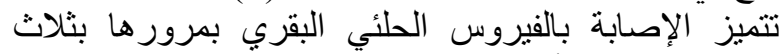

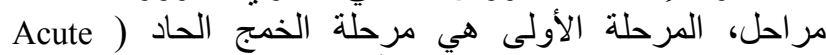
(Infection

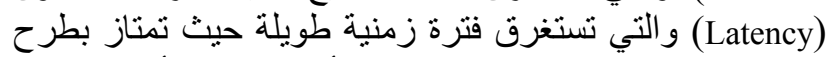

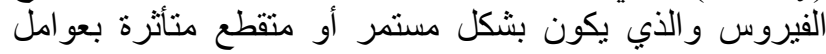

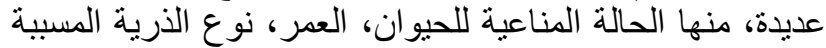

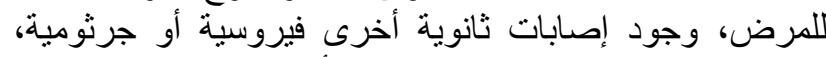

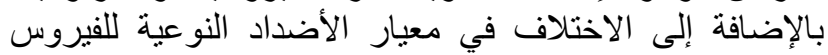

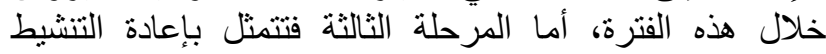
Reactivation

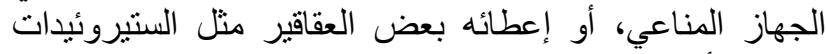
القشرية أو تعرض الحيو أعطان لعوامل بعض إلاجهاد (0)، تعد مرحلة العثئ 


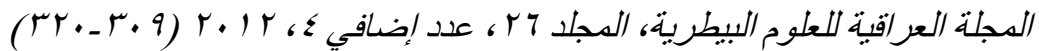

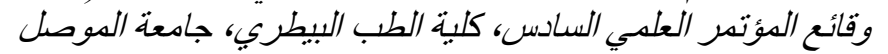

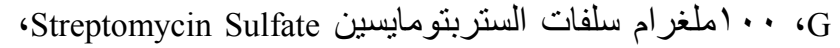

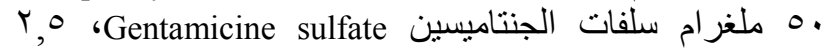

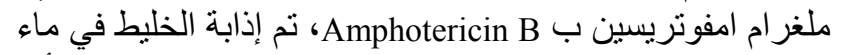

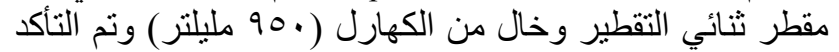

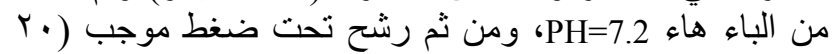

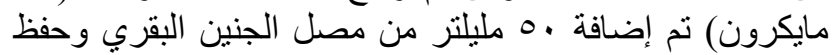

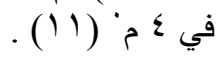

تحضير الوسط الزرعي للنمو

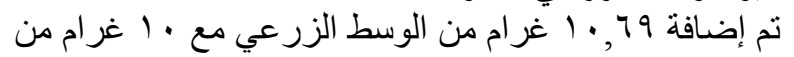

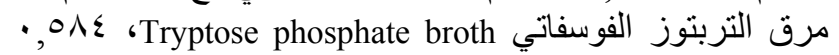

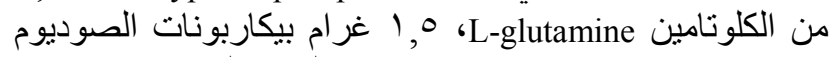

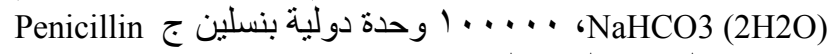

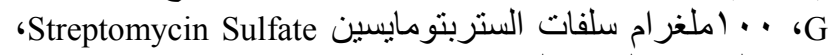

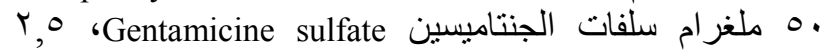

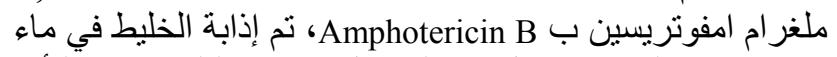

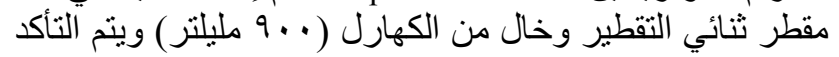

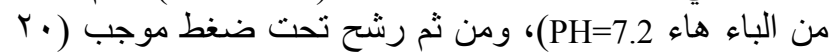

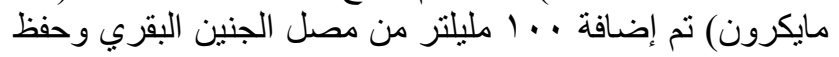

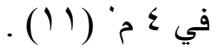

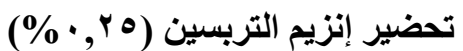

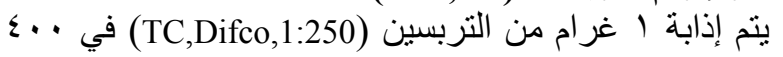

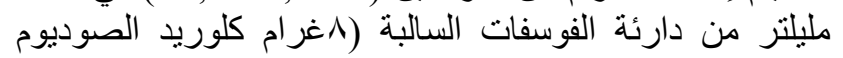
بل raCl

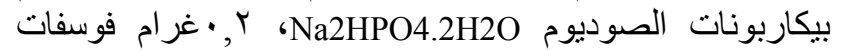

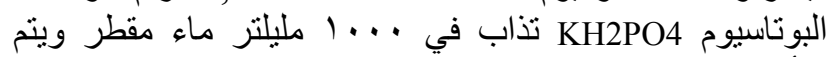

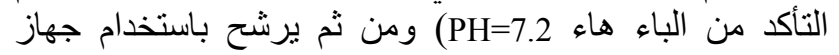

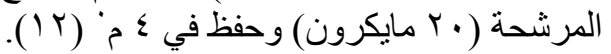

\section{تحضير محلول التربسين فرسين}

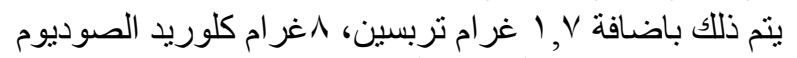

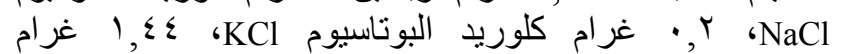

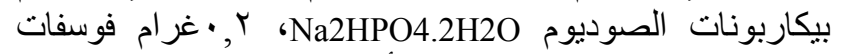

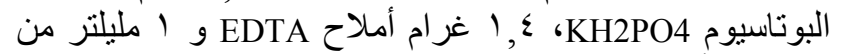

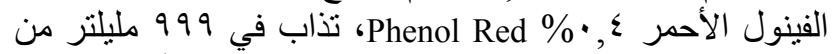
ماء مقطر ثنائي التقطير وخال من الكهارل ويتم التأكد من الباء

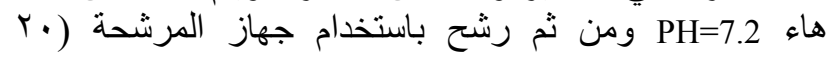

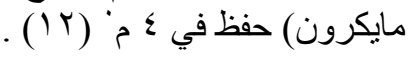

تحضير خلايا كلية أجنة الأبقار

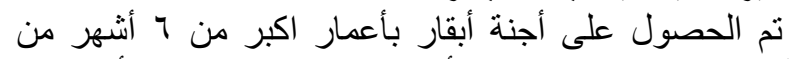

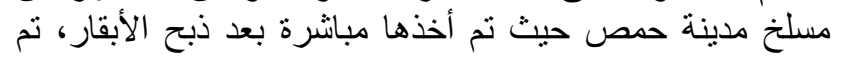

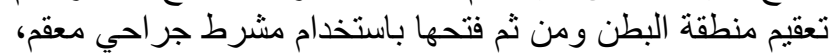

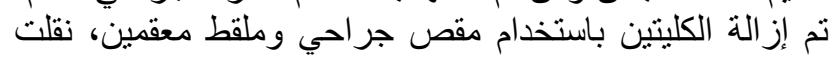

المحطات لغرض جمع البيانات التالية عن الحيوان حيث شملت الإجهات

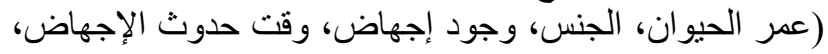

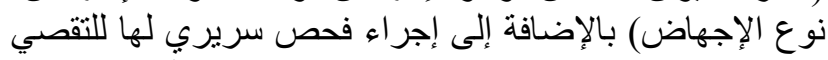

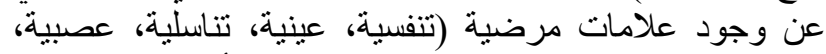

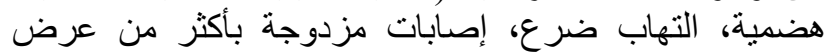
سريري أو كون الحيوان سليم ظاهريا) .

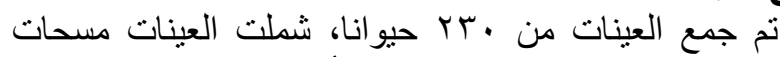

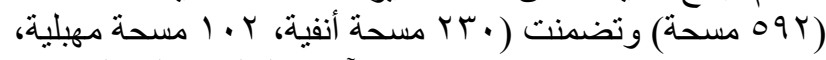

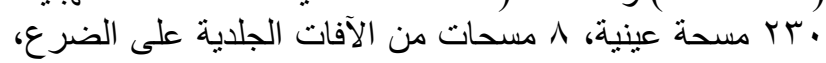

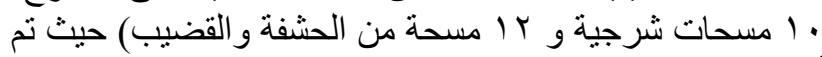

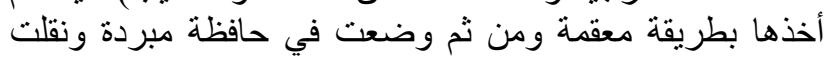

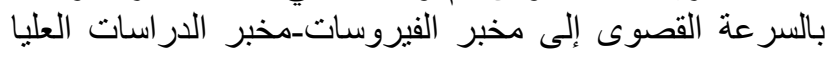

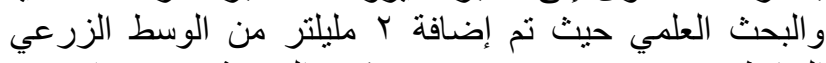

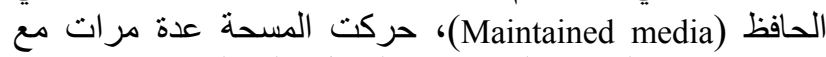

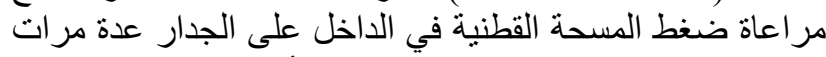

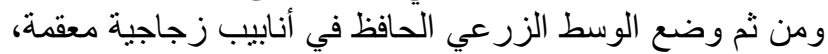

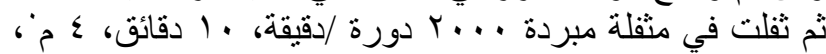

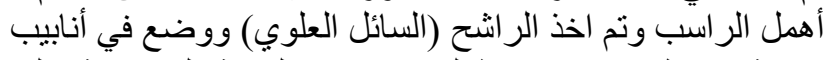

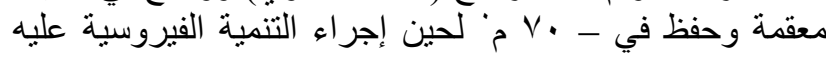

\section{تحضير مصل الجنين البقري}

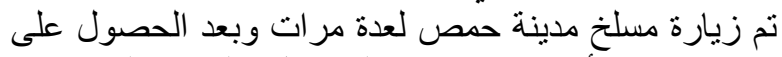

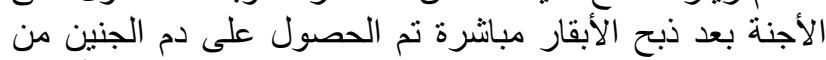

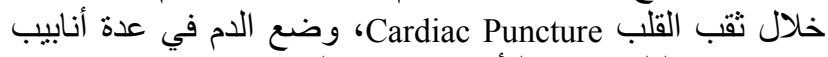

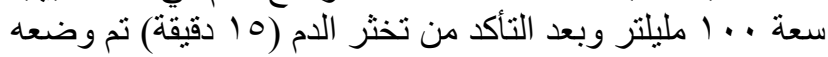

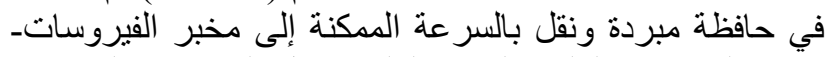

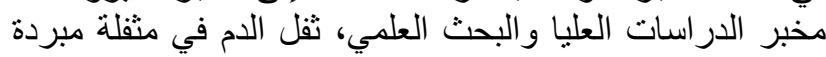

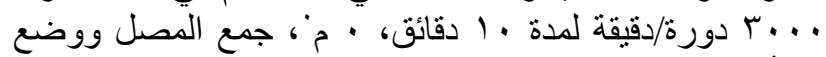

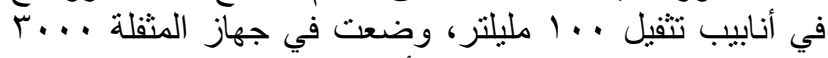

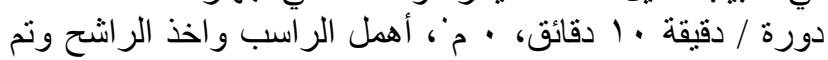

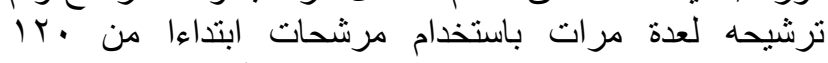

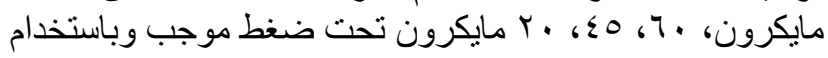

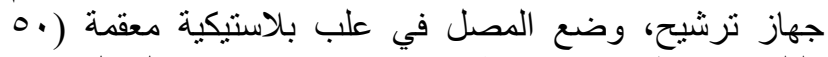

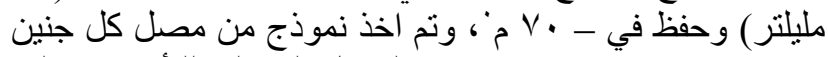

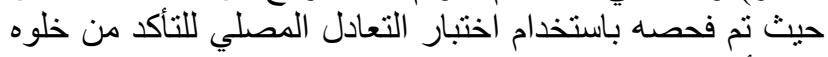
من الأضداد للفيروس الحلئي البقري النمطـ ا ــ، (• (1) .

تحضير الوسط الزرعي الحافظ

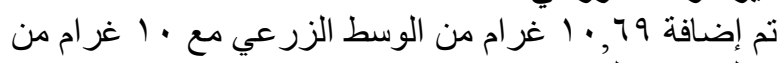

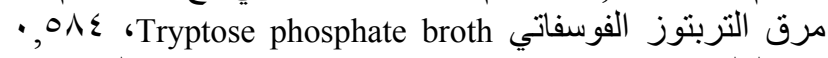

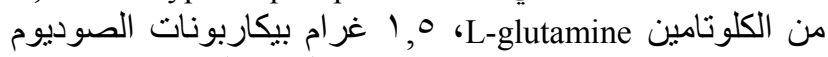

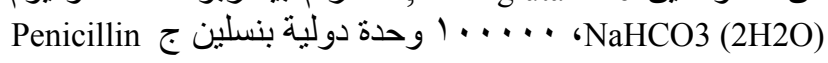




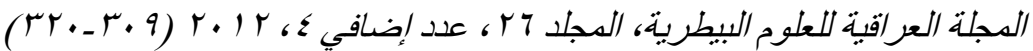

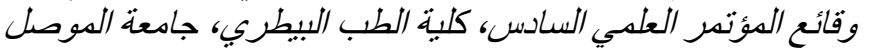

\section{تنمية الفيروس على خلايا كلية أجنة الأبقار}

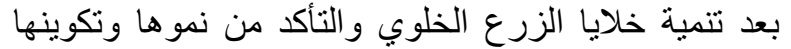

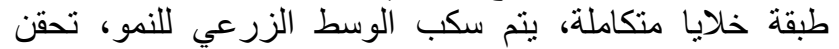

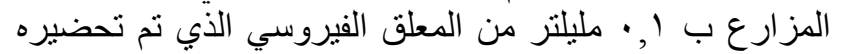

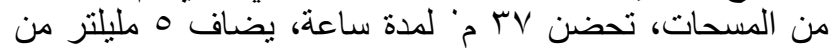

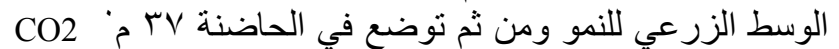

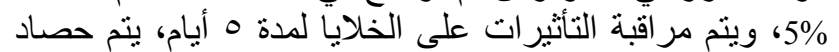

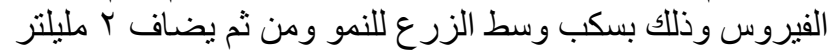

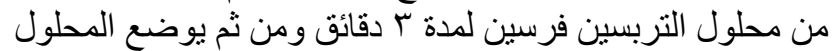

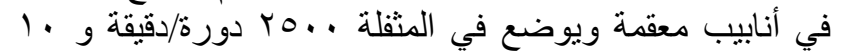

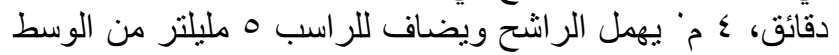

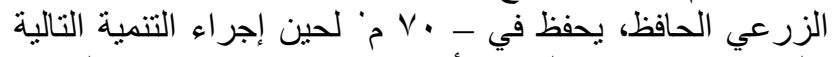

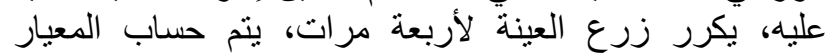

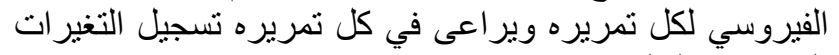
المرضية الخلوية (Cy) ووقت ظهور ها بعد الحقن بالساعات (ع ( ) .

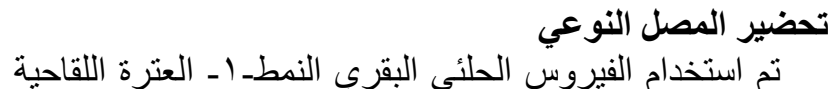

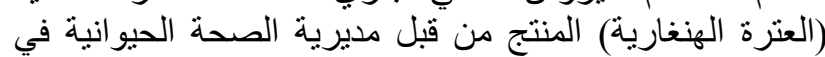

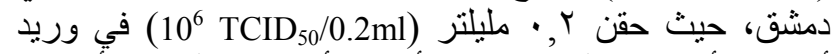

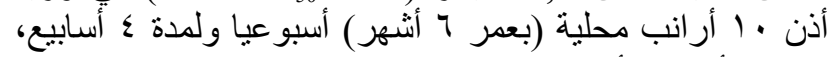
وبعد V أيام من أخر جر عة، تم الحصول على أكبر اكبر كمية دم منها

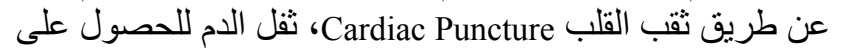

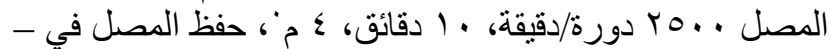

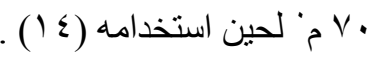

تثخيص الفيروس

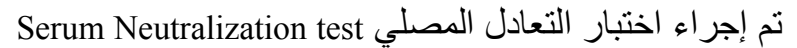
حسب طريقة (10) حيث يتم تحضين المصل المضاد المضاد المحضر

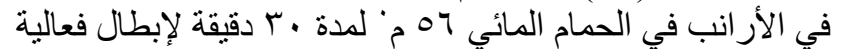

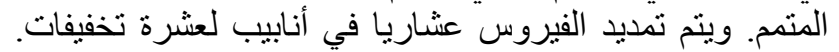

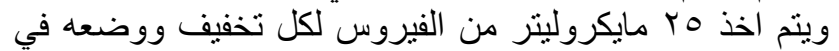

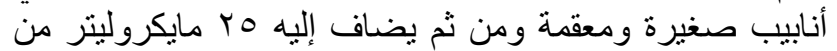

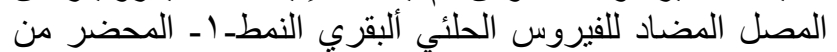

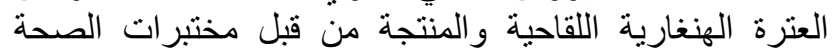

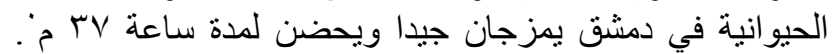
ويتم تحضير خلايا زرع نسجي من نون نوع خلايا كلية أجنة الأبقار

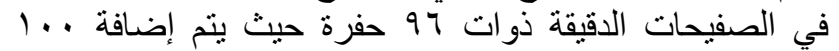

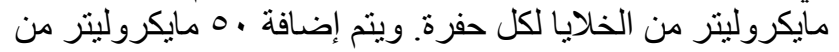

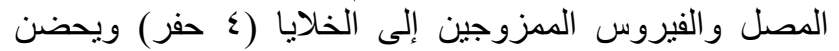

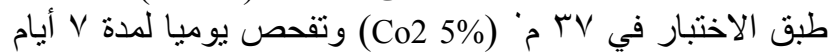

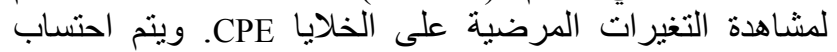

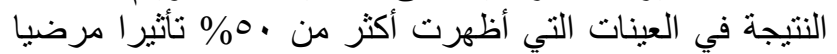
للخلايا إذ تعتبر النتيجة اليجابية.
الكليتين إلى حافظة بلاستيكية معقمة حاوية على الوسط الزر عي العي

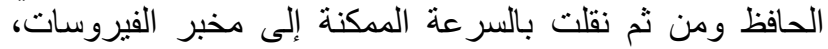

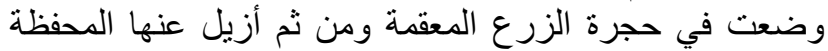

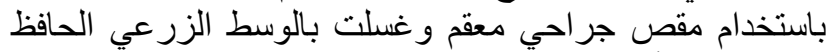

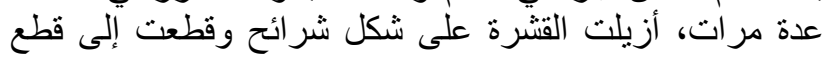

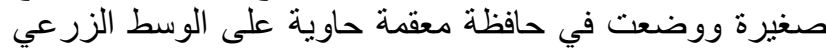

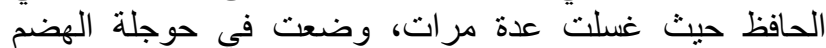
بالتربسين (Trypsnized flask) أضيف (إليها أنزيم التربسين

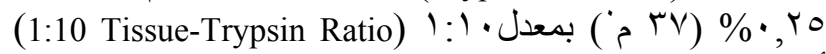
أضيف إليها قطعة مغناطيسية معقمة ووضعت فئس فوق جهاز المزج

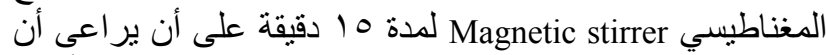
تكون سرعة جهاز المزج بطيئة للنع تكون الفقاعات، أهمل

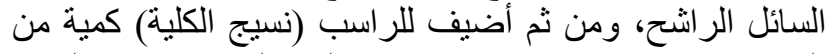

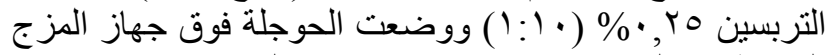

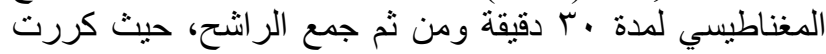

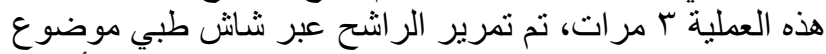

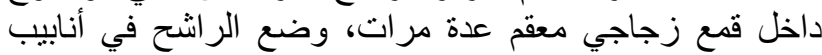

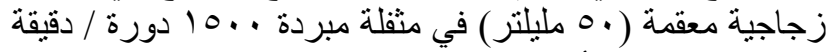

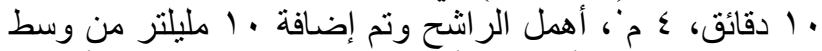

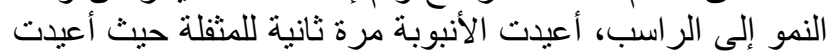

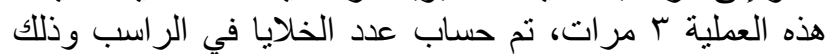

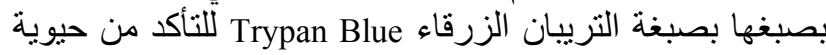

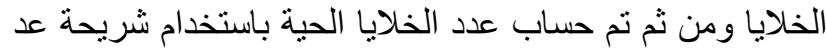

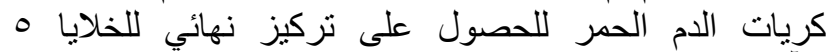

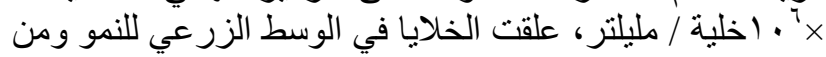

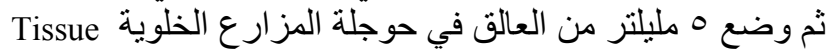

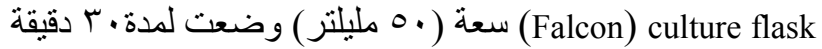

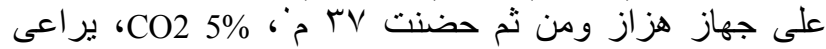

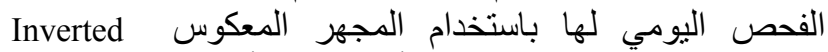
Microscope

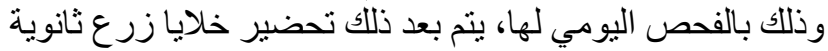
منها وذللك بسكب الوسط ا الزرعي للنمو ومن ثم ثم ينم إضافة

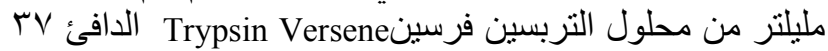

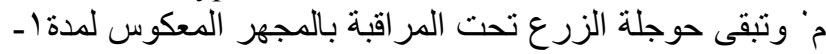

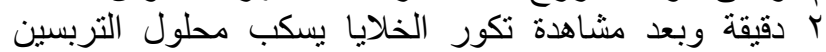

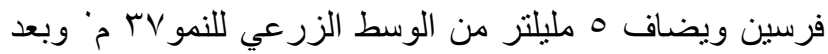

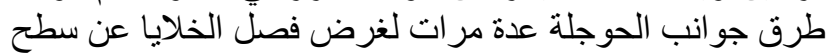

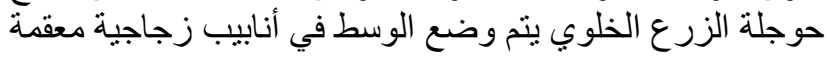

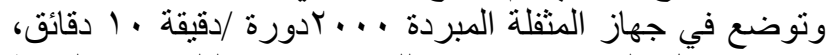

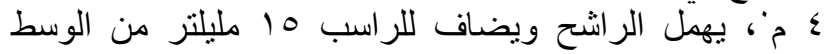

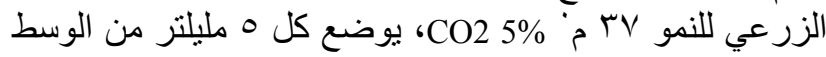

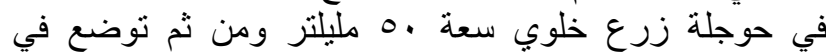

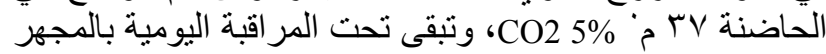

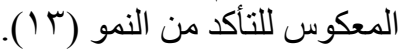




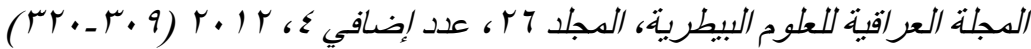

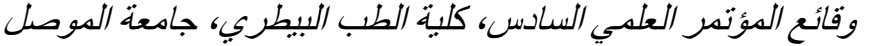

بلغت اقل نسبة إصابة في محطة درعا وبكلا الطريقتين أيضا"، وتباينت نسبة الإصابة في باقي المحطات، جدولـ إسة -ـ.

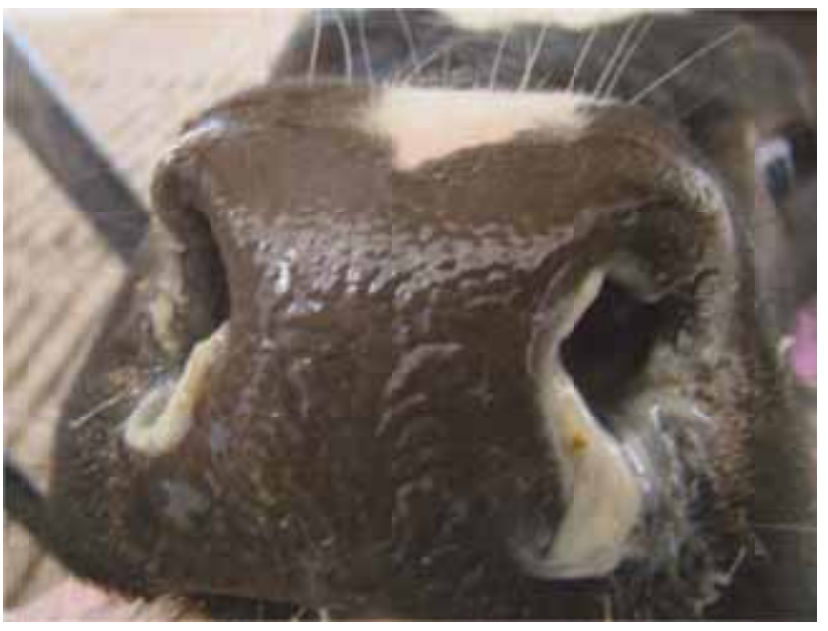

الشكلـ ا - يبين السيلانات الأنفية لعجل يبلغ اقل من 1 شهور.

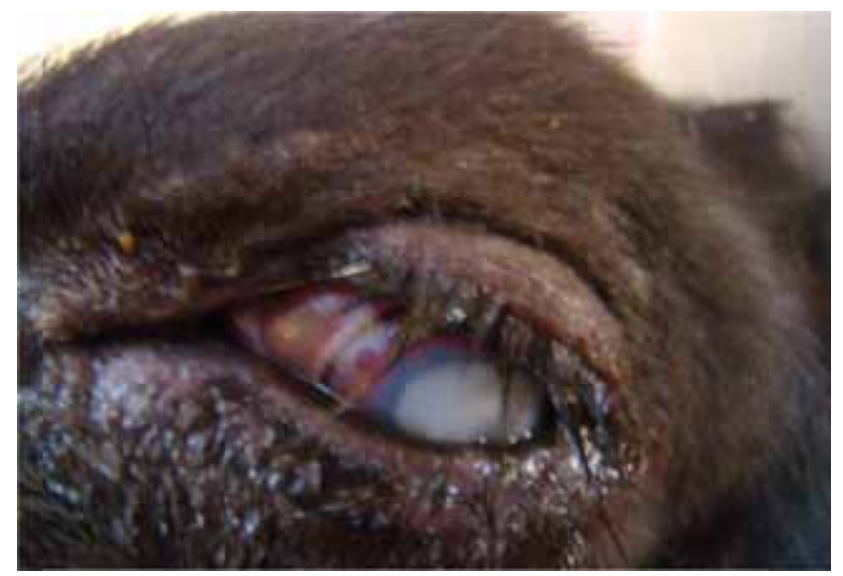

الشكل_r- يبين السبلانات من العين مع ابيضاضها و إصابتها بالعمى.

تبين من خلال النتائج أن أعلى نسبة إصابة كانت في

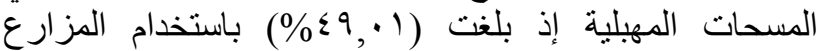

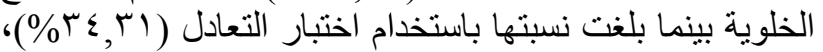

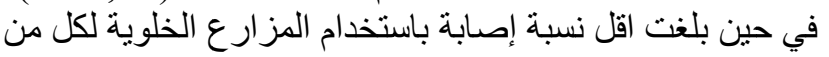

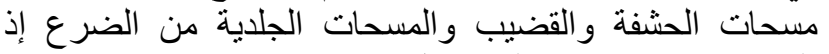
بلغت (\%)\% بينما بلغت اقل نسبة إصابة باستخدام اختبار

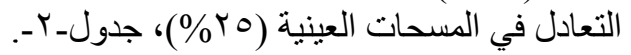

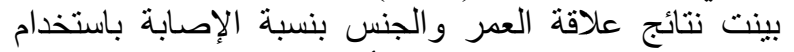

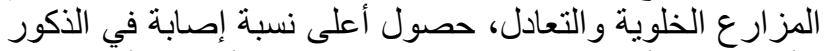

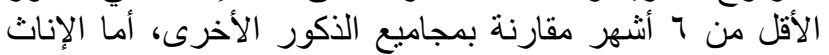

اختبار التعادل

لغرض معرفة معيار الفيروس الذي تم تنميته على خلايا

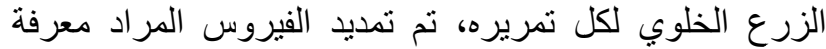

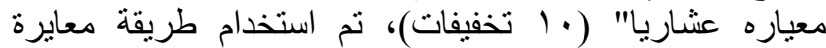

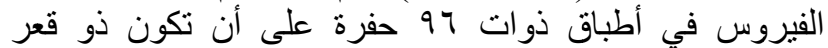

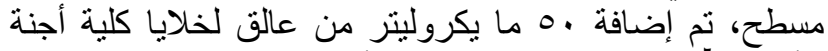

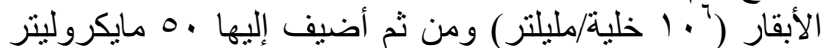

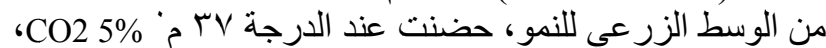

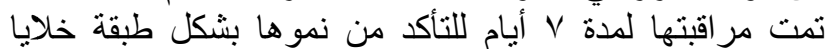
متكاملة، تم سحب الوسط الزرعي للنمو باستخدام ماصة دقيقة

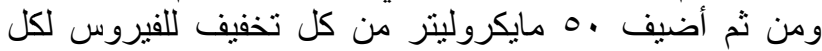

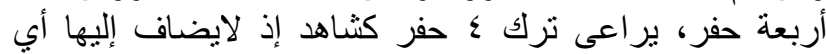

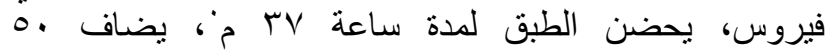

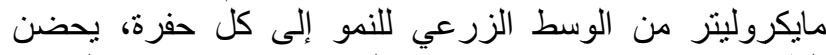

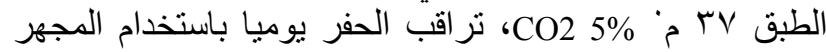

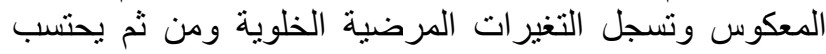
المعيار حسب طريقة Reed and Muench, 1938 ( 193

النتائج

بينت نتائج الفحص السريري للأبقار التي تم جمع العينات

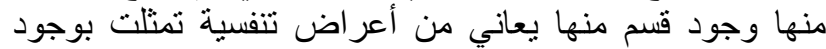

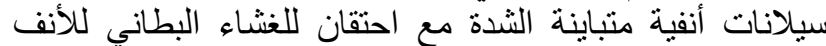

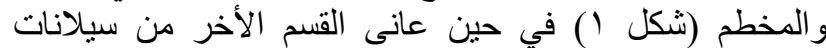

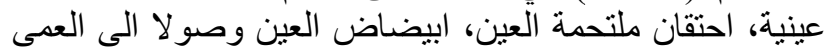

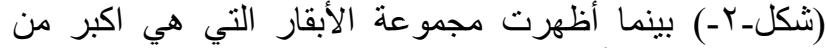

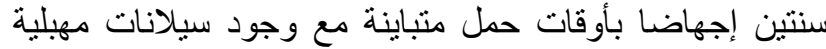

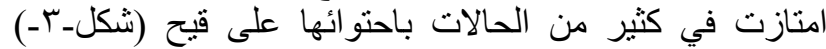
أظهرت بعض الثيران التي بلغت أعمار ها أكثر من سنتين

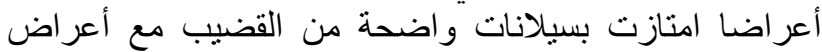

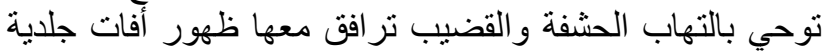

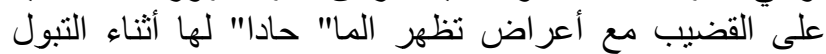

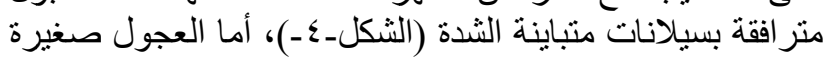

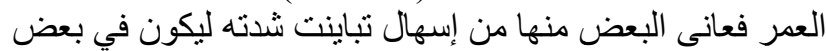

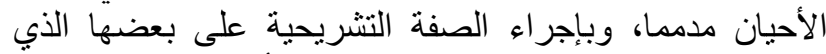

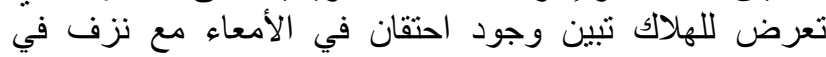

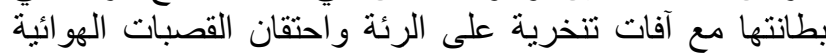

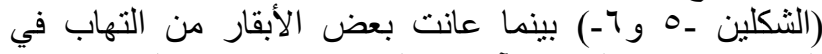
الضرع إضافة لوجود آفات جلدية مزمنة عانة عند البعض منها (الثكل - (- (-).

أظهرت نتائج عزل وتنخيص الفيروس الحلئي البقري النمطـ

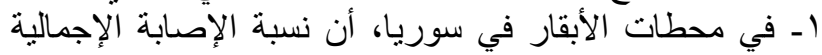

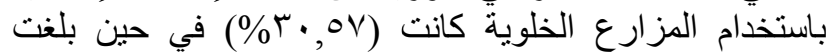

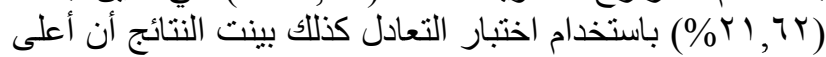

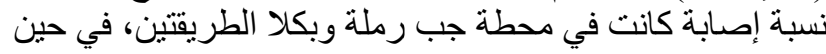




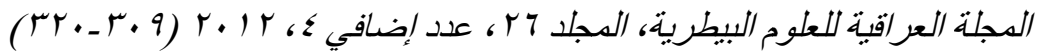

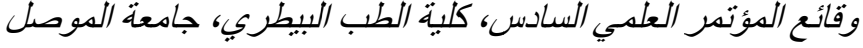

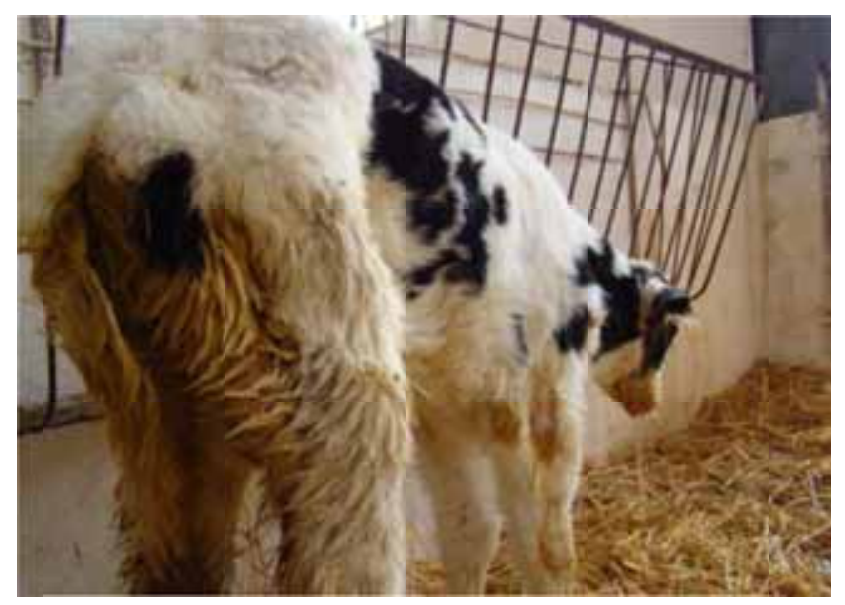

الثكل_ه- يبين إسهال في عجل اقل من شهرين.

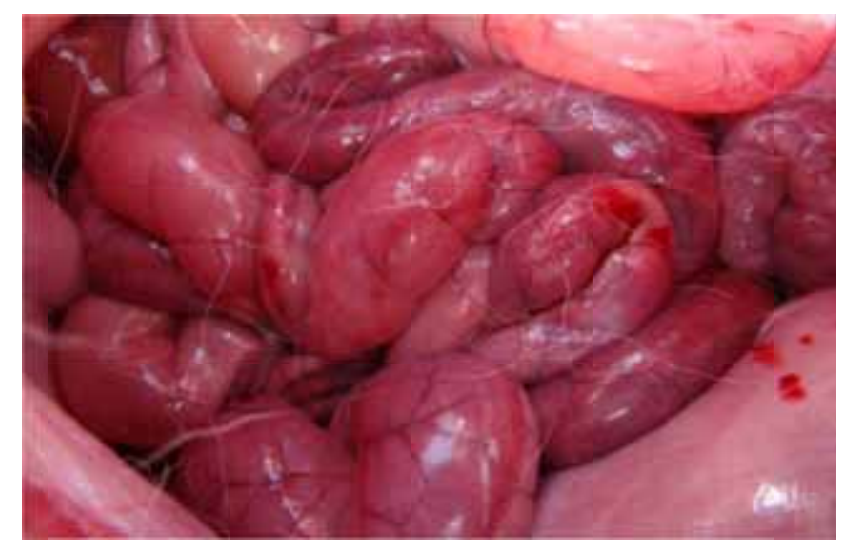

الثكل_- - يبين احتقان مع نزف في الأمعاء لعجل نافق.

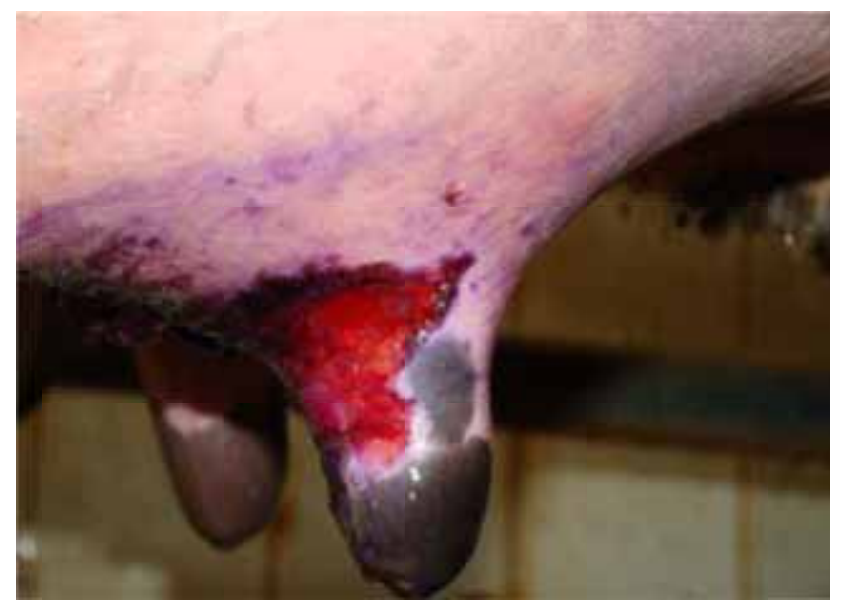

الثكل-V- يبين الآفات الجلدية على الحلمة لبقرة تم عزل
فبلغ أعلى نسبة إصابة في الإناث الأقل من 7 أنشهر وبكلا

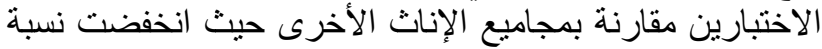

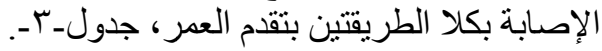

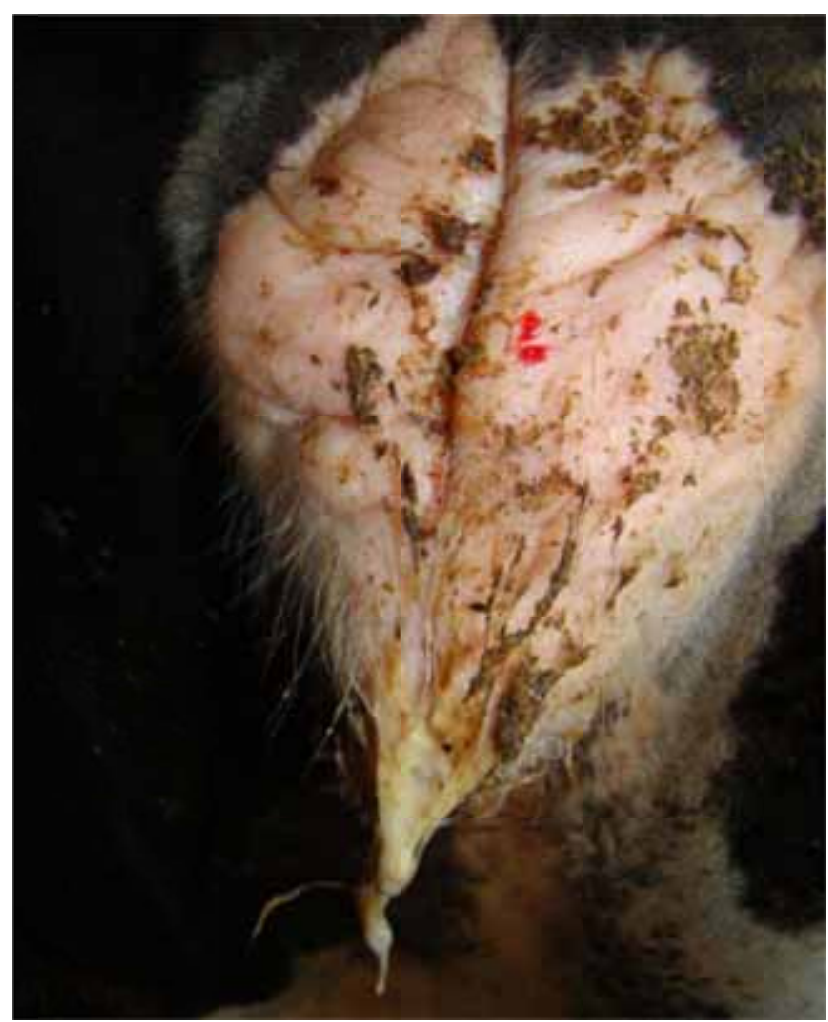

الثكل-؟ - يبين السيلانات المهيلية مصحوبا بالقيح لبقرة مصابة

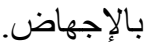

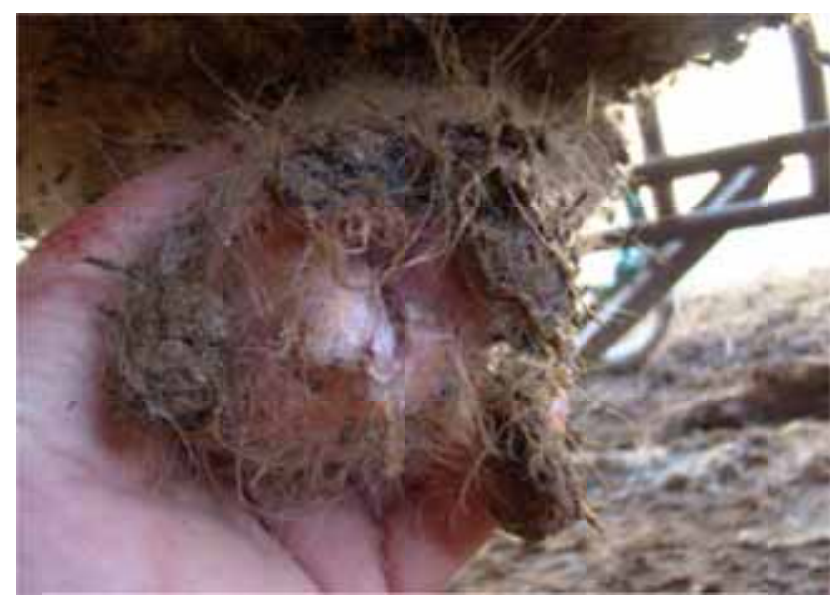

الشكل-ع - يبين السيلانات من القضيب مع تكون أغشية فيبرينية

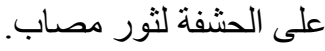




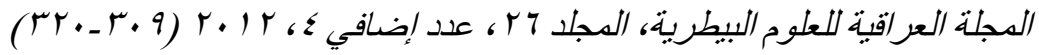

$$
\begin{aligned}
& \text { وقائع الهؤتمر العلمي السادم، كلية الطب البيطري، جامعة الهوصل }
\end{aligned}
$$

جدول ( (1): المقارنة مابين الاختبار ات المستخدمة لتشخيص الإصابة بالفيروس الحلئي البقري النمطـ ا ـ في محطات الأبقار في سوريا.

\begin{tabular}{|c|c|c|c|c|c|}
\hline 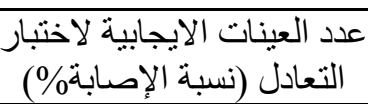 & 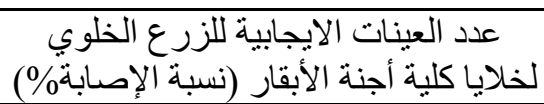 & (المسحدات) & 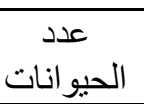 & المحطة & ت ت \\
\hline$\left(\Gamma_{0},{ }^{\prime}\right) r$. & $\left.(0, \wedge \vee)^{\prime}\right)^{\prime}$ & OV & $r$. & جب رملة & 1 \\
\hline$(r Y, \cdot V) \backslash V$ & $(r V, V \Psi) r$. & or & YY & جورين & r \\
\hline$(17, r r) \wedge$ & $(Y \cdot, \varepsilon) 1$. & $\leqslant 9$ & $r$. & حمص & r \\
\hline r & $(\Gamma \leqslant, \wedge \wedge) 10$ & $\varepsilon r$ & 19 & طرطوس & $\varepsilon$ \\
\hline$(r \tau, \wedge) ו r$ & $(\Gamma-90) \backslash V$ & $\leqslant 7$ & 19 & فيديو & 。 \\
\hline$(V, 79) \varepsilon$ & (19, $19 \pi)($. & or & $r$. & درعا & 1 \\
\hline$\left(Y_{0}\right) \mid \varepsilon$ & $(Y \wedge, O V) 17$ & 07 & YI & الغوطة & $\mathrm{V}$ \\
\hline$(I V, I \varepsilon) \backslash$ & $(r), \leqslant r) r r$ & $v$. & ro & مسكنة & $\wedge$ \\
\hline 9 & $(r T, \cdot V) I T$ & or & $r$. & الزربة & 9 \\
\hline$(10,01)^{9}$ & ג 1 (T, & $0 \Lambda$ & $r \varepsilon$ & تل تمر & 1 . \\
\hline$(\mid \vee, \wedge 0) 1$. & $(r), \leqslant r) \backslash r$ & 07 & $r$. & دير الزور & 11 \\
\hline$(Y, T Y) \backslash Y \wedge$ & $(r \cdot, \Delta V) \backslash \wedge)$ & 094 & rr. & المجموع & \\
\hline
\end{tabular}

جدول (r): عدد العينات الايجابية للمسحات المأخوذة من الأبقار باستخدام خلايا الزرع الخلوي لخلايا كلية اجنة الأبقار واختبار التعادل

في محطات الأبقار في سوريا.

\begin{tabular}{|c|c|c|c|c|c|c|c|c|c|c|c|c|}
\hline \multicolumn{2}{|c|}{ 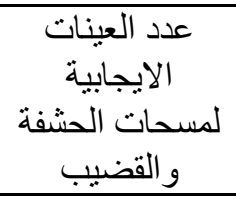 } & \multicolumn{2}{|c|}{ 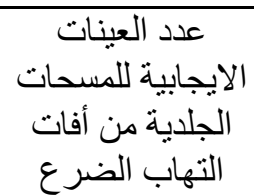 } & \multicolumn{2}{|c|}{ اللايجابية } & \multicolumn{2}{|c|}{ 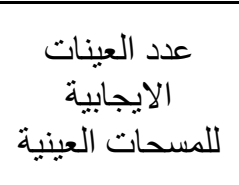 } & \multicolumn{2}{|c|}{$\begin{array}{c}\text { للمدد العينات } \\
\text { لايجابية المهبلية }\end{array}$} & \multicolumn{2}{|c|}{ 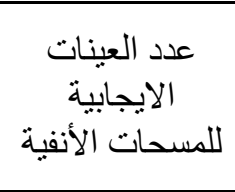 } & \multirow{2}{*}{ المحطة } \\
\hline التعادل & الزلايا & التعادل & الزلايا & التعادل & الخلايا & التعادل & الزلايا & التعادل & خلايا الزرع & التعادل & الزلايا & \\
\hline 1 & 1 & . & . & . & . & 7 & 9 & 0 & $\Lambda$ & $\Lambda$ & 11 & جب رملة \\
\hline 1 & 1 & . & . & . & . & r & 7 & $\varepsilon$ & $\varepsilon$ & 9 & 9 & جورين \\
\hline . & . & - & - & . & . & r & $r$ & $r$ & $r$ & $r$ & $\varepsilon$ & حمص \\
\hline . & . & . & 1 & . & . & $\varepsilon$ & 0 & r & r & 7 & 7 & طرطوس \\
\hline . & . & - & - & - & - & 0 & 7 & $\varepsilon$ & 7 & $r$ & 0 & فيديو \\
\hline . & . & 1 & 1 & . & . & 1 & 1 & 1 & $\varepsilon$ & 1 & $\varepsilon$ & در عا \\
\hline . & . & . & . & 1 & 1 & r & r & 0 & 7 & 0 & 7 & الغوطة \\
\hline . & . & . & . & 1 & 1 & r & V & $\varepsilon$ & 7 & 0 & $\wedge$ & مسكنة \\
\hline . & 1 & - & . & . & 1 & 0 & 0 & 1 & 1 & r & $\varepsilon$ & الزربة \\
\hline . & . & - & - & . & . & r & 7 & $r$ & 0 & $\varepsilon$ & V & تل تمر \\
\hline . & . & . & . & . & . & $r$ & $r$ & $r$ & $\varepsilon$ & $\varepsilon$ & 0 & دير الزور \\
\hline$r$ & $r$ & 1 & $r$ & $r$ & $\mu$ & rq & $0 \leqslant$ & ro & 0. & 01 & 79 & المجموع \\
\hline 17,77 & ro & $1 T, 0$ & ro & $r$. & $r$. & 10,70 & $r r, \leqslant V$ & $r \leqslant, r)$ & $\leqslant 9,+1$ & $r Y, I V$ & $r$. & $\%$ \\
\hline
\end{tabular}

التغيرات المرضية الخلوية فتميزت بحصول انتفاخ في الخلايا

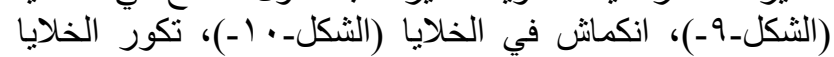

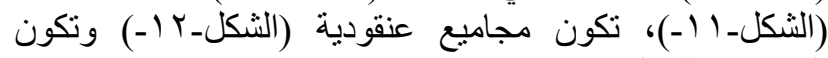

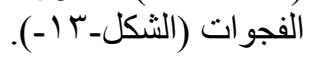

بينت نتائج تتمية الفيروس على خلايا كلية أجنة الأبقار

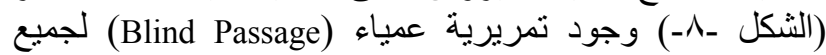

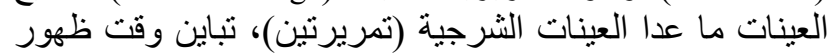
الآفات المرضية حيث قل الوقت بتقدم التمريرات، تبات، أما نوع 


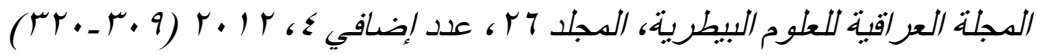

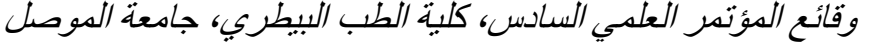

جدول (־): يبين علاقة العمر و الجنس بنسبة الإصـابة بالفيروس الحلئي البقري النمطـ ا ـ باستخدام المز ارع الخلوية واختبار التعادل.

\begin{tabular}{|c|c|c|c|c|c|}
\hline 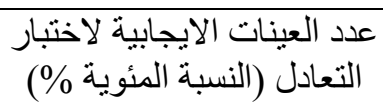 & 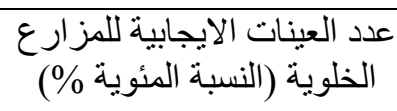 & العدد & نوع المسحات & 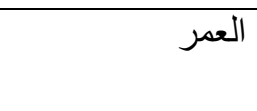 & الجنس \\
\hline$(r \cdot, q 7) \mid r$ & $\left(r^{q}, \cdot r\right) \backslash \wedge$ & $r \cdot$ & تنفسية & اقل من 7 شهور & \\
\hline$(\wedge, \cdot 7)^{\circ}$ & $(r \cdot, 97) ו r$ & r. & عينية & & \\
\hline$(1,71) 1$ & $(1,71) 1$ & r & شرجية & & الذكور \\
\hline$(r \cdot, 7 \varepsilon) 19$ & $(01,7){ }^{\prime}$ & $T Y$ & المجموع & & \\
\hline$(\wedge, q r)^{\circ}$ & $(\mid \vee, \wedge 0) 1 \cdot$ & TV & تنفسية & T شهور Y سنة & \\
\hline$\left(0, r_{0}\right) r$ & $(1 \leq, r \wedge) \wedge$ & rV & عينية & & \\
\hline$(\cdot) \cdot$ & $(\cdot) \cdot$ & r & شرجية & & \\
\hline$(1 \leqslant, Y \wedge) \wedge$ & $(T r, I \varepsilon) \backslash \wedge$ & 07 & المجموع & & \\
\hline$(11,11) \leq$ & $(0 \cdot)^{7}$ & IT & تنفسية & اكبر من سنتين & \\
\hline$(11,11) \leq$ & $(11,11) \varepsilon$ & ir & عينية & & \\
\hline$(0,00) r$ & $(\Lambda, r r) r$ & ir & مسحات حشفة وقضيب & & \\
\hline$(K V, V V)) \cdot$ & $(r 4,11) 1 r$ & ru & المجموع & & \\
\hline$(I V, 07) \mid \Gamma$ & $(T \cdot, Y V) 10$ & ro & تنفسية & اقل من 7 شهور & \\
\hline$(1 \cdot, \wedge) \wedge$ & $\left(17, Y^{\prime}\right)(r$ & ro & عينية & & \\
\hline$\left(1, \Gamma_{0}\right) 1$ & $\left(1, \Gamma_{0}\right) 1$ & $\varepsilon$ & شرجية & & \\
\hline$\left(Y^{q}, V Y\right) Y Y$ & $(\Gamma \vee, \wedge r) r \wedge$ & $V \varepsilon$ & المجموع & & الإناث \\
\hline(\rceil$, \vee \vee) \varepsilon$ & $(1 \cdot, 17)^{7}$ & $r \varepsilon$ & تنفسية & T شهور-Y سنة & \\
\hline$(\wedge, \leqslant \vee)^{\circ}$ & $(\wedge, \Sigma \vee)^{\circ}$ & $r \leq$ & عينية & & \\
\hline$(\cdot) \cdot$ & $(1,79) 1$ & r & شرجية & & \\
\hline$(0, \cdot 1) r$ & $(\wedge, \leqslant \vee)^{\circ}$ & 9 & مهبلية & & \\
\hline$(T \cdot, r T) \backslash Y$ & $(Y \wedge, \wedge)) \backslash V$ & 09 & الهجموع & & \\
\hline$(0, \Sigma)^{7}$ & (\urcorner$, r)^{V}$ & rq & تنفسية & 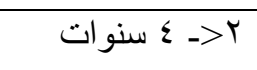 & \\
\hline$(r, v) r$ & $(\varepsilon, 0) 0$ & rq & عينية & & \\
\hline rו & $(10, \pi)(V$ & r. & مهبلية & & \\
\hline$(\cdot) \cdot$ & $(\cdot, 9) 1$ & r & جلدية من الضرع & & \\
\hline$(19,11)$ Yr & $(Y V, \cdot r) \Gamma$. & 111 & الهجموع & & \\
\hline$(\varepsilon, Y r) 0$ & $(\varepsilon, Y r) 0$ & rᄉ & تنفسية & ع > V سنوات & \\
\hline$(r, r) \leq$ & $(r, r) \leq$ & ऍᄉ & عينية & & \\
\hline$(1 \cdot, 17) \backslash$ & $(17,1) 19$ & rᄉ & مهبلية & & \\
\hline$(\cdot, \wedge \varepsilon) 1$ & $(\cdot, \wedge \varepsilon) 1$ & $\varepsilon$ & جلدية من الضرع & & \\
\hline$(\backslash \wedge, T \varepsilon) Y Y$ & $(Y \leqslant, 0 V) Y q$ & 111 & المجموع & & \\
\hline$(Y, T /)^{\prime}$ & $(Y, T T) Y$ & Yo & تتفسية & اكبر من V سنوات & \\
\hline$(r, 9 \leq) r$ & $(r, q \leq) \Gamma$ & ro & عينية & & \\
\hline$(1 \cdot, 0 r) \wedge$ & $(11, \wedge \varepsilon) q$ & ro & مهبلية & & \\
\hline$(\cdot) \cdot$ & $(\cdot) \cdot$ & 1 & جلدية من الضر ع & & \\
\hline$(I V, I) \backslash T$ & $(1 \wedge, \varepsilon r) \backslash \varepsilon$ & $V 7$ & المجموع & & \\
\hline
\end{tabular}




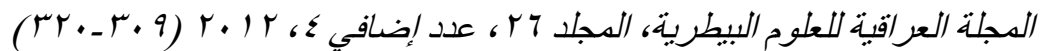

$$
\begin{aligned}
& \text { وقائع الهؤتصر العلمي السادم، كلية الطب البيطري، جامعة الهوصل }
\end{aligned}
$$

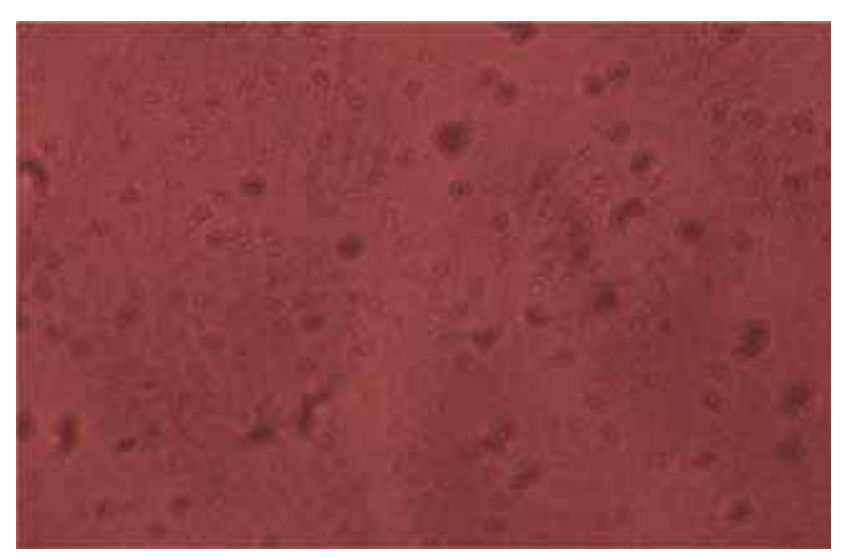

الثكل- I ــ تكور خلايا كلية أجنة الأبقار بعد حقنها بالفيروس.

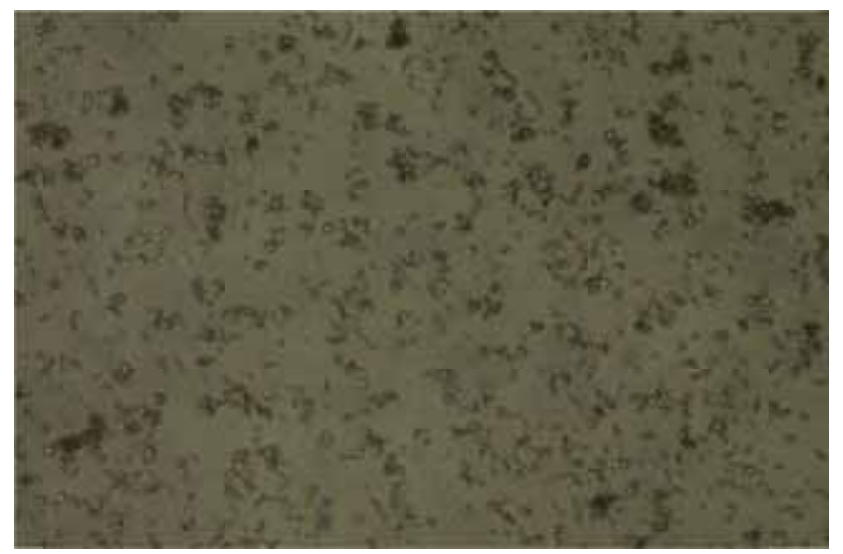

الثكل-Y I ـ تكون مجاميع عنقودية من خلايا كلية أجنة الأبقار

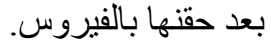

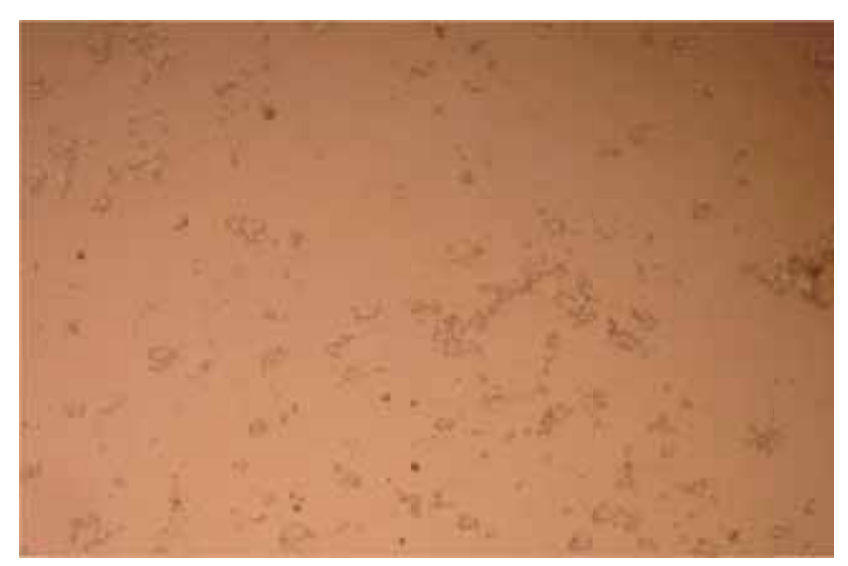

الثكل_r ا ـ تكون فجوات في خلايا كلية أجنة الأبقار بعد حقنها

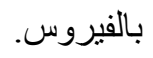

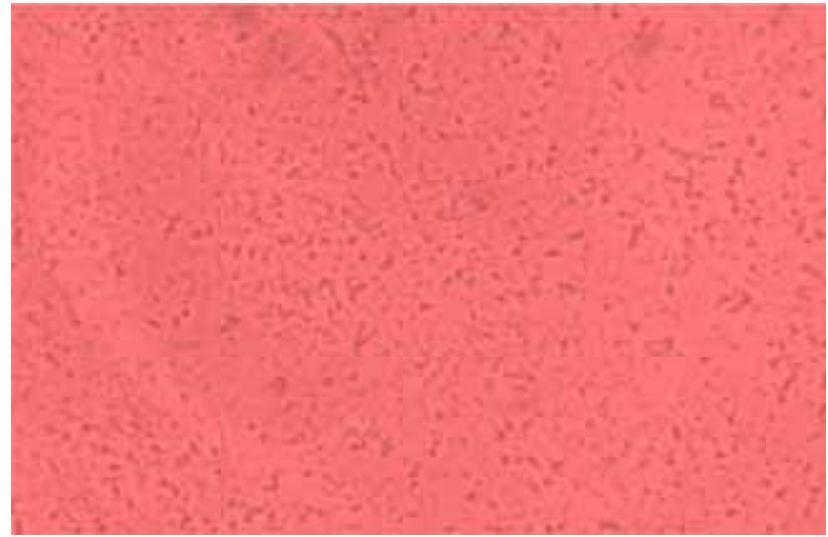

الثكل_^_ خلايا كلية أجنة الأبقار قبل حقنها بالفيروس.

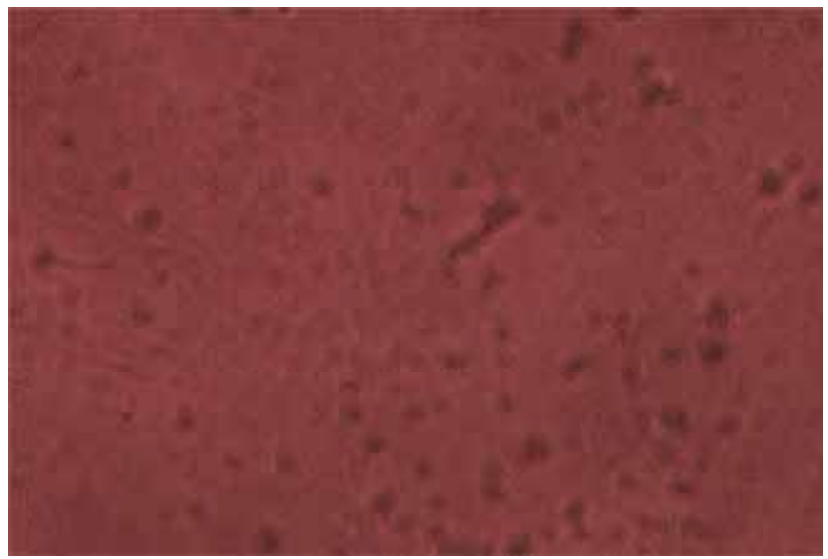

الثكل_9 ـ انتفاخ خلايا كلية أجنة الأبقار بعد حقنها بالفيروس.

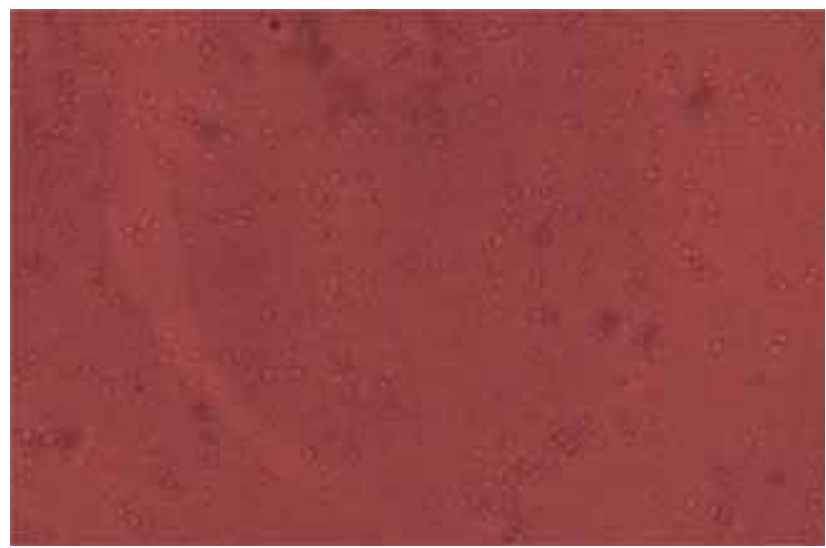

الثكلــ • ــ انكماش خلايا كلية أجنة الأبقار بعد حقنها بالفيروس. 


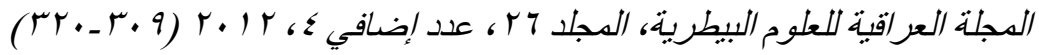

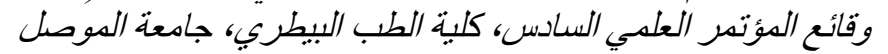

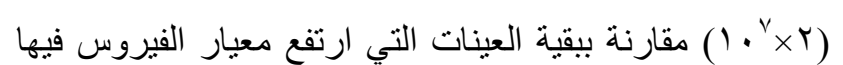

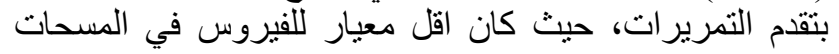

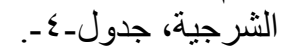

إن التغيرات المرضية الخلوية كانت متباينة في ظهور ها في

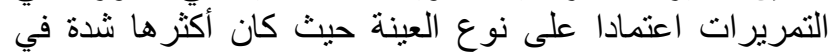

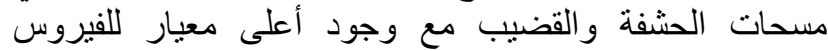

جدول (ع): يبين نتائج تنمية العينات (المسحات) بأنو اعها على خلايا كلية أجنة الأبقار مع بيان نوع التغيرات المرضية الخلوية مع وقت ظهور ها بالساعات، ومعيار العزو لات لكل تمريرة.

\begin{tabular}{|c|c|c|c|c|c|c|c|c|c|c|c|c|c|}
\hline \multirow{2}{*}{ 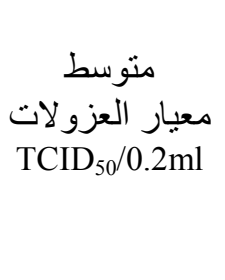 } & \multicolumn{5}{|c|}{ التغيرات المرضية الخلوية } & \multicolumn{4}{|c|}{ وقت ظهور التغير ات الخاعاتة } & \multirow[t]{2}{*}{ العزو لات } & \multirow[t]{2}{*}{ رالتمريرة } & \multicolumn{2}{|c|}{ صدر العينة } \\
\hline & فونون & تكون & الخلايا & النكالشا & الخلايا & $V Y$ & $\overline{\varepsilon \wedge}$ & $\mu$. & 11 & & & & \\
\hline . & . & . & . & . & . & . & . & . & . & . & الأولى & مسحات & 1 \\
\hline $1 r^{r} \times r$ & . & . & $\varepsilon$ & r & 10 & 0 & 7 & 11 & . & $r r$ & الثانية & أنفية & \\
\hline $1 r^{r v} \times r$ & . & r & 7 & $1 \varepsilon$ & $r$. & سו & $1 \varepsilon$ & 17 & . & $\varepsilon r$ & الثالثة & & \\
\hline $10^{0,0} \times r$ & . & $\wedge$ & 1. & 1. & rז & 7 & r & $r r$ & 1. & 01 & الر ابعة & & \\
\hline . & . & . & . & . & . & . & . & . & . & . & الأولى & مسحات & r \\
\hline $10^{3.5} \times r$ & - & - & 0 & r & $\wedge$ & $r$ & r & 11 & . & 10 & الثانية & مهبلية & \\
\hline $10^{5.5} \times Y$ & . & r & $\varepsilon$ & 7 & 10 & $r$ & 7 & $\wedge$ & 11 & $r \wedge$ & الثالثة & & \\
\hline $10^{6.5} \times r$ & 1 & $\varepsilon$ & 0 & 7 & 19 & V & 7 & V & 10 & ro & الر ابعة & & \\
\hline . & - & - & - & - & - & . & . & . & . & . & الأولى & مسحات & $r$ \\
\hline $1 .{ }^{1}{ }^{r} \times Y$ & . & . & . & 7 & $\pi$ & 7 & 0 & $\wedge$ & . & 19 & الثانية & عينية & \\
\hline $1, r, r \times r$ & . & r & r & r & $1 \varepsilon$ & 7 & 0 & 1. & . & YI & الثالثة & & \\
\hline $1.0^{\varepsilon, \varepsilon} \times r$ & . & 7 & $\wedge$ & 1. & IT & V & 1. & $1 \leq$ & 0 & ד r & الر ابعة & & \\
\hline . & . & . & . & . & . & . & . & . & . & . & الأولى & مسحات & $\varepsilon$ \\
\hline - & . & - & . & . & . & . & . & . & . & - & الثانية & شرجية & \\
\hline $1 .{ }^{\prime}{ }^{\prime} \times r$ & - & - & . & . & 1 & 1 & . & . & . & 1 & الثالثة & & \\
\hline $10^{r, \varepsilon} \times r$ & . & . & . & 1 & 1 & 1 & 1 & . & . & r & الر ابعة & & \\
\hline$\therefore$ & . & . & . & . & . & . & . & . & . & . & الأولى & مسحات & 0 \\
\hline $1 . r,{ }^{9} \times r$ & - & - & - & 1 & - & . & 1 & . & . & 1 & الثانية & جلدية من & \\
\hline $1 . r, \varepsilon \times r$ & . & . & . & 1 & . & . & . & 1 & . & 1 & الثالثة & الضرع & \\
\hline $10^{\circ},{ }^{\prime} \times r$ & . & . & 1 & . & . & . & . & 1 & . & 1 & الر ابعة & & \\
\hline . & - & . & . & . & . & . & . & . & . & . & الأولى & مسحات & 7 \\
\hline $1, r, r \times r$ & . & . & 1 & . & . & . & . & 1 & . & 1 & الثانية & الحثفة & \\
\hline $1 .{ }^{\varepsilon, T} \times Y$ & 1 & 1 & . & . & . & . & . & 1 & 1 & $r$ & الثالثة & و القضيب & \\
\hline $1{ }^{V} \times Y$ & $r$ & . & . & . & . & . & . & . & r & $r$ & الر ابعة & & \\
\hline
\end{tabular}

الأعمار والأجناس، حيث تبين أن نسبة الإصابة الكلية في

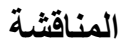

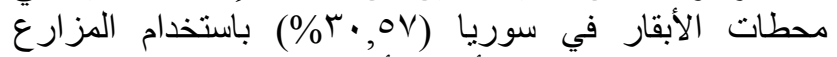

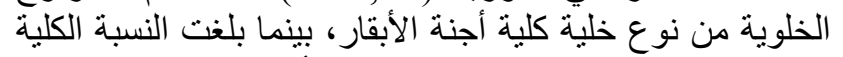

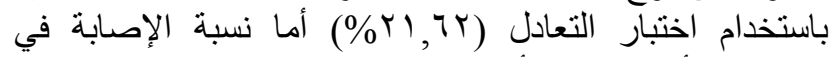

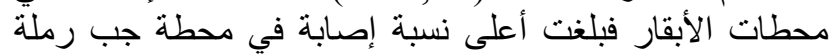
وبكلتا الطريقتين بينما بلغت القل نسبة إبلة إصابة في محطة أبقار

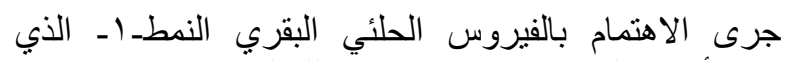

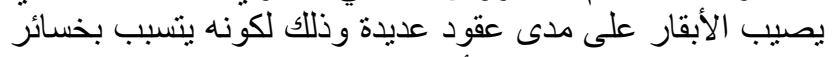

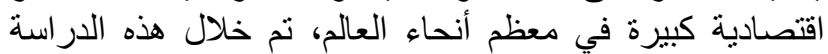

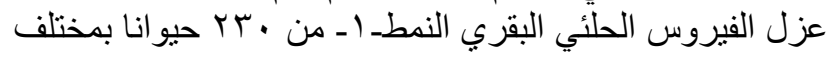




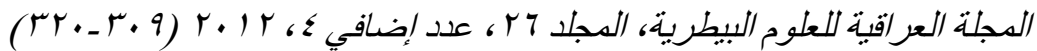

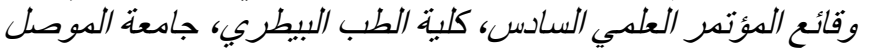

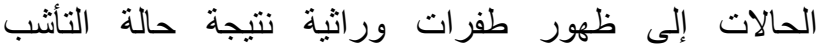
Recombination

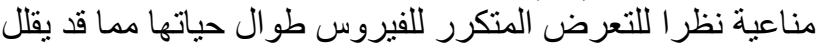

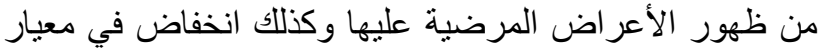

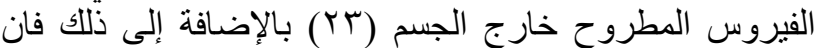

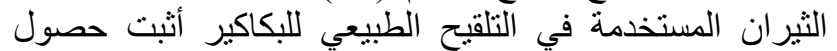
إصابة فيها في دراستناً الحالية.

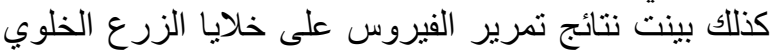
وجود تمريرة واحدة عمياء فيما عدا عينات الفيرون المسحات الثيات الثرجية

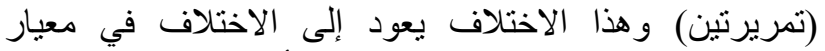

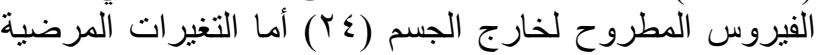

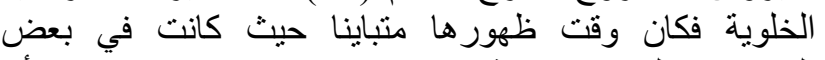

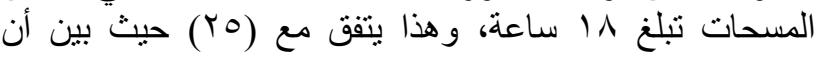

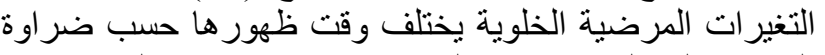

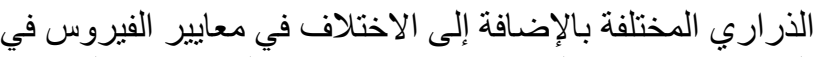

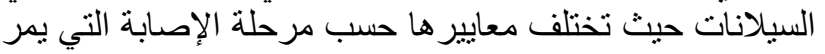
بها الفيروس حيث تكون مرتفعة في مرحلة الإصابة الحادية الحادية

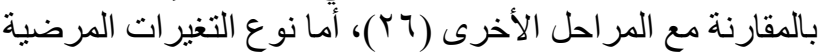

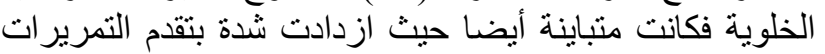

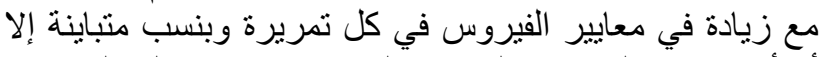

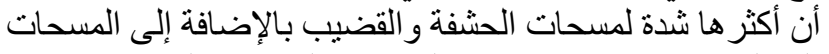

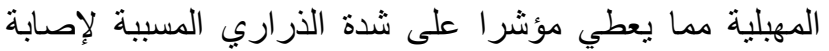

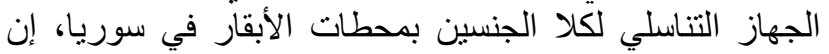

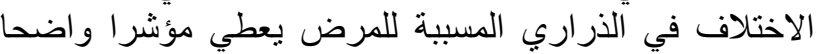

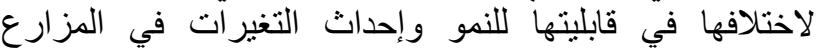

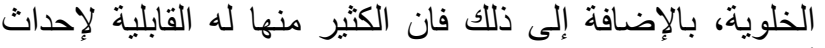

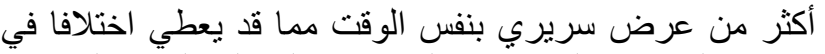
معايير الفيروس المطروح بالسيلانات المختلفة لنفس الحيو الحيوان،

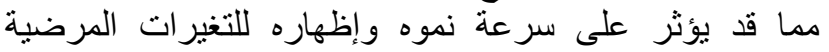

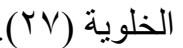

يتبين من خلال هذه الدراسة وجود إصابة بالفيروس الحلئي

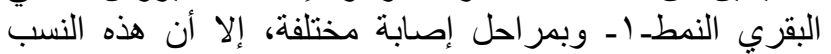

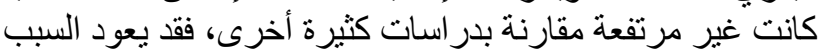

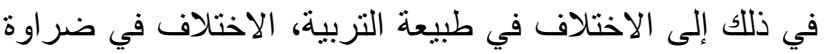

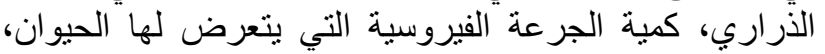

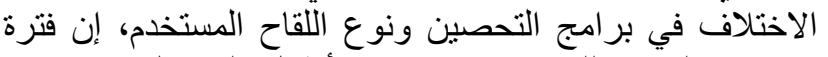
الإصابة الكآمنة للفيروس تكون من الطين أطول المراحل الكل من ناحية

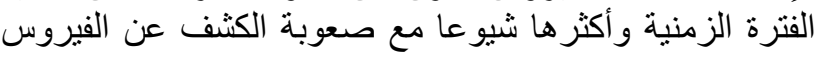

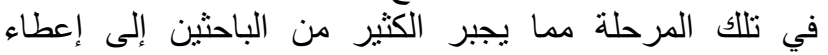

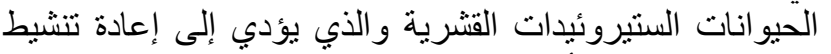

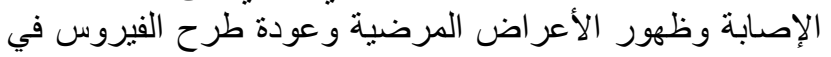

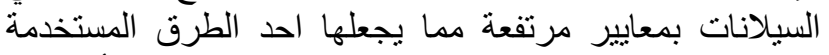

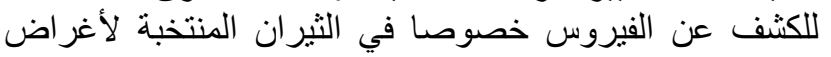
التلقيح الاصطناعي.
در عا وبكلنا الطريقتين أيضا، توجد محاولة واحدة لعزل الفي الفيروس

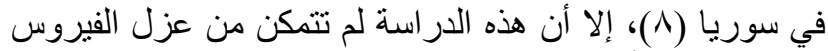

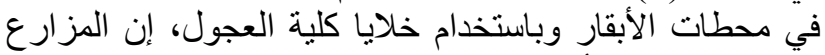

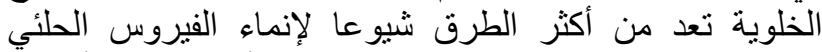

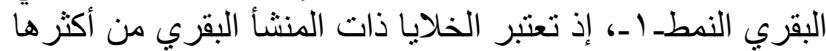

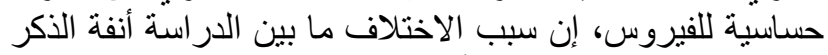

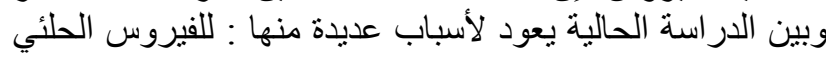

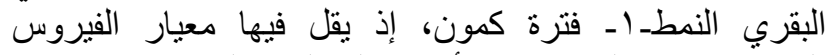

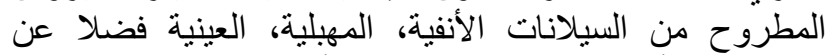

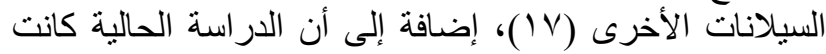

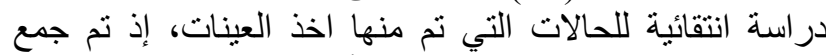

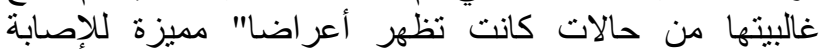

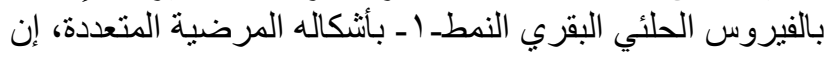

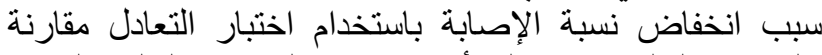

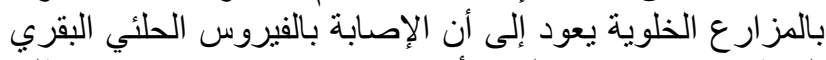

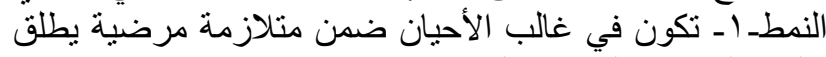

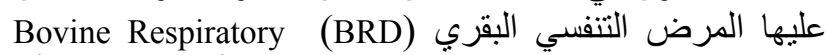
حيث يكون ضمن مسبباته فيروسات أخرى يمكنها أن الن النئ (Bisease تنمو على المزارع الخلوية (1/).

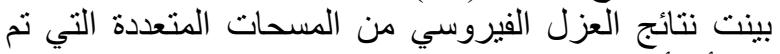

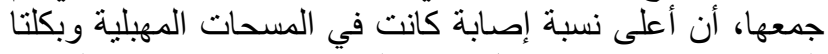

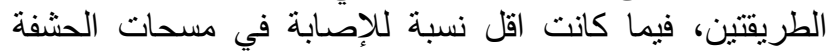

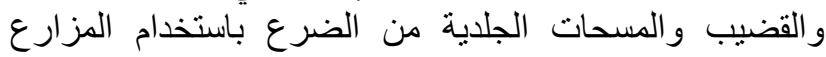

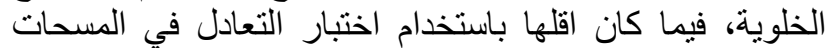

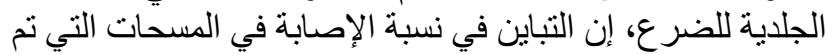

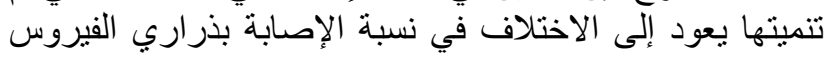

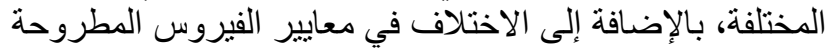

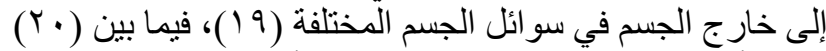

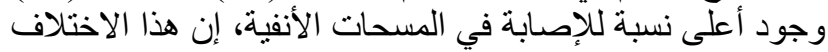

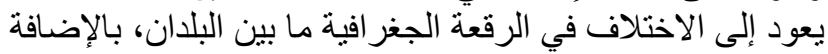

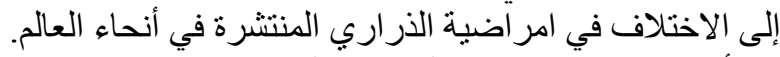

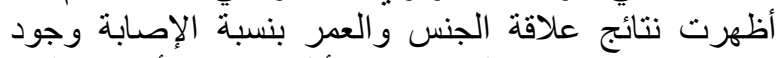

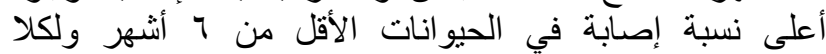

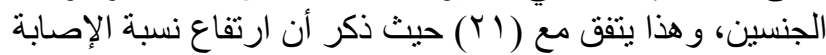

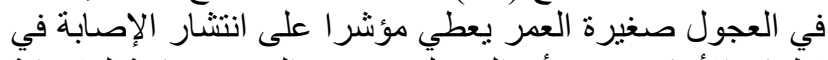

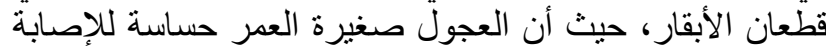

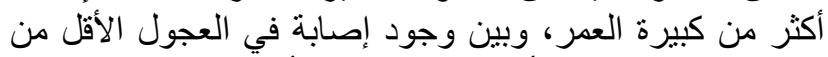

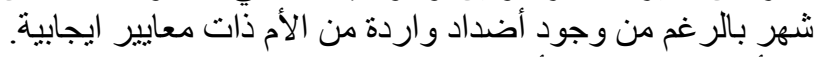

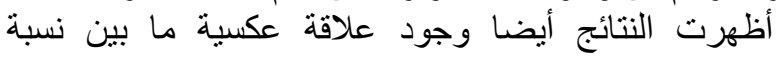

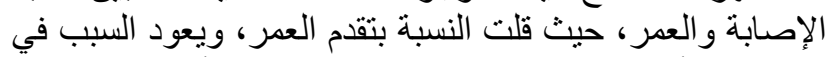
ذللك إلى الأخطاء في نظم التربية، حيث تلقح الأبية الأبقار (البكاكير)

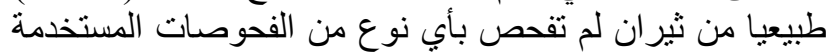

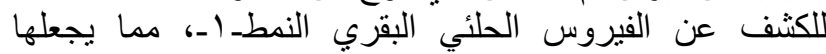

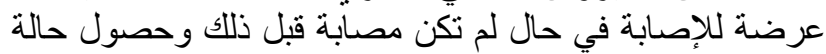
الإصابة الإضافية Super infection مما قد يؤدي في بعض فل فل في 


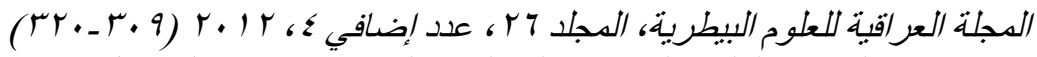

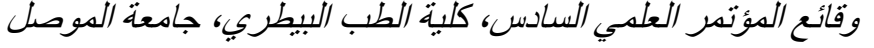

Untersuchungen.Veterrinary Medicine thesis,University of Zurich.2001,1-67.

15. Amira ME,Fadol MA, Karrer AE, Elhussin ARM. IBR Virus in Sudan:Epidemiological and Serological studies.Journal of Anim. and Vet. Adv..2006;5 (12) :1053-1057.

16. Benoit M, Julien T, Philippe K, Frederic S, Etienne T. Bovine Herpesvirus 1 infection and infectious bovine rhinotrachitis.Vet. Res.2007; 38:181-209.

17. Joze G, Peter H, Ivan T, Darja BM. Molecular detection of BHV-1 in artificially inoculated semen and in the semen of a Latently infected bull treated with dexamethasone. Vet J. 2005;23 (2) :112-118.

18. Clinton J, Shafiqul C.A. Review of the biology of bovine herpesvirus Type $1(\mathrm{BHV}-1)$, its role as a cofactor in the bovine respiratory disease complex and development of improved vaccines. Ani. Heal. Res. Rev.2007;8 (2) :187-205

19. Bosco DJC, Tracy AC, Michael LD, Simon JM. Aspects of Bovine herpesvirus-1 infection in dairy and beef herds in the Republic of Ireland. Acta Vet. Scand.2011;53 (1) :40-51.

20. Grady LON, Collins DCT, More S. Herd within -herd BoHV-1 Prevalence among Irish beef herds submitting bulls for entry to a Performance testing station. Irish Vet. J.2008;61:809-815.

21. Dubois E, Duquesne V, Gastaldi C, Del Cont Aurelie VM, Thiry R.Strategy for IBR monitoring and herd qualification in France. Czech Vet Med.2010;22:60-68.

22. Meurens F,Schynts F,Keil GM, Muylkens B,Vander-Plasschen A, Gallego P, Thiry E.Superinfection Recombination of the alphaherpesvirus bovine Herpesvirus 1. J Virol.2004;78 :3872-3879.

23. Nandi S, Kumar M, Manohar M, Chauhan RS.Bovine herpesvirus Infection in cattle. Ani Heal Res Rev.2009;10 (1) :85-98.

24. Penny CD, Sargison ND, Howie F. Upper respiratory disease And encephalitis in neonatal beef calves caused by bovine Herpesvirus 1 . Vet Rec.2002;151:89-91.

25. Meyer G, Lemaire M, Ros C. Comparative pathogenesis of acute And latent infections of calves with bovine herpesvirus 1. Arch Virol.2001;146:633-652.

26. Lovato L,Inman M,Henderson G,Doster A, Jones A.Infection Of cattle with a bovine herpesvirus 1 strain that contains a Mutation in the latency -related gene leads to increased Apoptosis on trigeminal ganglia during the transition from Acute infection to latency. $\mathrm{J}$ Virol.2003;77:4848-4857.

27. Kirkland XPD,Davis RJ, Hornitzky CL. Australian strains of Bovine herpesvirus 1 are genetically homogenous. World Association of Veterinary laboratory Diagnosticans- $13^{\text {th }}$ International. Symposium, Melbourn, Australia. 2007;11-14 Sep

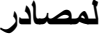

1. Ackermann M, Engels $M$. Pro and contra IBR eradication. Vet Microbiol. 2006;113 (4) :293-302.

2. Ata A, Kale M,Yavru S, Bulut O, Buyukyoruk U. The Effect of subclinical bovine herpesvirus 1 infection on fertility of cows and heifers.Acta Veterin. (Beograd) .2006; 56 (3) :267-273.

3. Yavru S,Ozturk F,Simsek A,Yapkic O, Yildiz CIsolation of bovine herpesvirus type 1 from bovine semen in Turkey Revue Med Vet. 2001152 (9) :633-636.

4. Fernando RS, Ana CF, Frans AMR, Rudi W, Edusrdo FF,Paulo MR.In vitro characterization of $\mathrm{gE}$ negativeBovine herpesvirus types 1.1 (BHV-1.1) and 1.2a (BHV-1.2a) . Brazilian J Microbiol. 2004;35:264-268.

5. Thiry J,Kruser V,Muylkens B,Meurens F,Gogev S, Vanderplasschen A,Thiry E.Ruminant alphaherpesviruses related to Bovine herpes virus1.Vet. Res. 2006 ; 37:169-190.

6. Winkler MTC, Doster A, Jones C.Persistence and Reactivation of bovine herpes virus -1 - in the tonsils of Latently infected calves.J.Virol.2000;74 (11) :5337-5346.

7. Van SDH, Myers DPA, Doig BK, Habermehl M, Babiuk LA, Jelinski M, Van DJ, Schlesinger K, RinehartC. Identification of a mutant bovine herpesvirus-1 (BHV-1) in Post -arrival outbreaks of IBR in feedlot calves and protection With conventional vaccination.Candian J Vet. Res.2001;65:81-88

^. الياس ينو ياسين و العدر أنور.عزل فيروس مرض التهاب الأنف

و الرغامى المعديIBR عند الأبقار في سورية (قيد النشر , مجلة جامعة فرئ

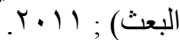

9. Mahmoud MA,Nahed AM, Allam AM. Investigation on Infectious bovine rhinotrachitis in Egyptian cattle and Buffaloes Global Veterin.2009; ,3 (4) :335-340.

10. Rai A.Methods in veterinary virology ,Indian Vet. Res Institute,India.2005 PP:50-52.

11. Mhan KM, Rajasekhar M, Krishnappa G. Isolation of infectious Bovine rhinotrachitis virus in Karnataka.Indian Vet. J. 1994;71 (2) : 109-112.

12. Dispas M, Schynts F, Lemaire M, Letellier C,Vanopdenbosch E, Thiry E, Kerkhofs P.Isolation of a glycoprotein E deleted bovine herpes virus 1 strain in field.Vet.Rec. 2009;153:209-212.

13. Rai A.Laboratory manual of cell culture and animal virology, Indian Veterinary research Institute.India.2008;PP:8-12.

14. Wyss SK.Etablierung und Anwendung einer auf der restriktionenzym analyse basierenden cluster- technik und einer datenbank des Bovinen herpesvirus typ 1 fur molekular $\quad-$ epidemiologische 